This PDF is a selection from an out-of-print volume from the National Bureau of Economic Research

Volume Title: Population and Economic Change in Developing Countries

Volume Author/Editor: Richard A. Easterlin, ed.

Volume Publisher: University of Chicago Press

Volume ISBN: 0-226-18027-1

Volume URL: http://www.nber.org/books/east80-1

Publication Date: 1980

Chapter Title: Recent Population Trends in Less Developed Countries and Implications for Internal Income Inequality

Chapter Author: Simon Kuznets

Chapter URL: http://www.nber.org/chapters/c9670

Chapter pages in book: (p. 471 - 516) 


\title{
8 \\ Recent Population Trends in Less Developed Countries and Implications for Internal Income Inequality
}

\author{
Simon Kuznets
}

In a recent paper (Kuznets 1976) I explored the effects on the conventional measures of distribution of income among households of demographic elements such as the size and changing composition of households through their life cycle. The exploration emphasized the need to take explicit account of these demographic elements in any attempt to observe trends in the long-term levels of income differentials-particularly those associated with economic growth, since the latter is usually accompanied by marked shifts in the size and age-of-head distributions of households. Of particular interest was the negative association between per capita income and size of the household or family, found also within the age-of-head classes and thus persisting through the household's life-span. If this cross-sectional association is translated into comparisons of per capita income for households of differing average size over the life-span, the result is a negative association between the per capita income and size variables. Since, in turn, size of households or families is largely a function of the number of children, the negative association just noted is also one between lifetime per capita income and fertility_provided that the differentials in fertility dominate differentials in mortality, as they did in the small sample of countries for recent years used in the cross section in my recent paper.

The present paper deals with a different, though related, question. Given the major population trends observable in recent decades in the

Simon Kuznets is professor of economics, emeritus, Harvard University, and consultant to the Economic Growth Center, Yale University

This research was supported in part by AID contract otr-1432 and aided by the Rockefeller Foundation grant RF 70051 to Yale's Economic Demography program.

The author is indebted to Yoram Ben-Porath of the Hebrew University of Jerusalem for helpful comments on an earlier draft of this paper. 
economically less developed countries (LDCs), what can one infer about the possible effects on long-term levels or changes in them in the internal distribution of incomc? For obvious reasons of scarcity of relevant data, and even more of the complex interactions between the population trends and the concurrent structural changes in the economy and society of the countries involved, any answer to the question just raised is bound to be speculative. But there may be value in at least trying to formulate the question unambiguously and in attempting some explicit, relevant speculation.

\subsection{The Major Population Trends}

One must begin by stressing that the acceleration in the population growth ratc in the LDCs, and their markedly higher rate of natural increase than in the economically more developed countries (MDCs), are recent historical trends-as is clearly indicated in table 8.1. Such recency, and the brevity of the period over which these trends have prevailed, compared with the preceding centuries of quite different demographic patterns, are basic to the understanding and evaluation of both the trends and their implications.

Table 8.1 shows that from the mid-eighteenth century through 1920 , the rate of increase (overwhelmingly, of natural increase) in the LDCs was at relatively low level, varying from less than a $0.1 \%$ to about $0.5 \%$ per year (see col. 5 , lines $12-24$ ). ${ }^{1}$ Throughout this long period of some seventeen to eighteen decades, the population growth rate in the MDCs was substantially higher-ranging from over $0.4 \%$ to well over $1 \%$ per year; and showed a marked acceleration already in the first half of the nineteenth century. It is only since the 1920 s that the rates of natural increase in the LDCs rose to approach those in the MDCs; they began to exceed the latter in the 1930s and 1940s, when severe economic recession and then World War II reduced population growth in the developed countries; and only since the 1950s have the annual growth rates of the LDCs climbed to well over $2 \%$, while those in the MDCs declined by the early 1970 s to less than $1 \%$. Thus, the acceleration and growth excess of population movements in the LDCs were within a relatively short span of about five decades, following centuries of growth at low rates that would look like stagnation by modern standards.

The second important aspect of these recent trends is that the acceleration, and the resulting excess in the rates of natural increase in the LDCs over those in the MDCs, was due wholly, or almost wholly, to the decline in the death rates - rather than to any movements in the birthrates. A summary of the trends of these vital rates taken separately, but unfortunately limited to the years since 1937, is presented in table 
Table 8.1 Growth of Population, Economically Less Developed (LDC) and More Developed (MDC) Countries, 1750-1975

\begin{tabular}{|c|c|c|c|c|c|c|}
\hline & Dates & $\begin{array}{l}\text { World } \\
\text { (1) }\end{array}$ & $\begin{array}{l}\text { MDCs } \\
\text { (2) }\end{array}$ & $\begin{array}{l}\text { LDCs } \\
\text { (3) }\end{array}$ & $\begin{array}{l}\text { China } \\
\text { (4) }\end{array}$ & $\begin{array}{l}\text { Other } \\
\text { LDCs } \\
\text { (5) }\end{array}$ \\
\hline \multicolumn{7}{|c|}{ A. Absolute Totals (in millions) } \\
\hline 1. & 1750 & 791 & 201 & 590 & 200 & 390 \\
\hline 2. & 1800 & 978 & 248 & 730 & 323 & 407 \\
\hline 3. & 1850 & 1,262 & 347 & 915 & 430 & 485 \\
\hline 4. & 1900 & 1,650 & 573 & 1,077 & 436 & 641 \\
\hline 5. & 1920 & 1,860 & 673 & 1,187 & 476 & 711 \\
\hline 6. & 1930 & 2,069 & 758 & 1,311 & 502 & 809 \\
\hline 7. & 1940 & 2,295 & 821 & 1,474 & 533 & 941 \\
\hline $8 a$. & $1950 a$ & 2,515 & 858 & 1,658 & 563 & 1,095 \\
\hline $9 a$. & $1960 a$ & 2,998 & 976 & 2,022 & 654 & 1,368 \\
\hline $8 b$. & $1950 b$ & 2,501 & 857 & 1,644 & 558 & 1,086 \\
\hline $9 b$. & $1960 b$ & 2,986 & 976 & 2,010 & 654 & 1,356 \\
\hline 10. & 1970 & 3,610 & 1,084 & 2,526 & 772 & 1,754 \\
\hline 11. & $\begin{array}{l}1975 \text { (proj. } \\
\text { med. var.) }\end{array}$ & 3,967 & 1,132 & 2,835 & 838 & 1,997 \\
\hline \multicolumn{7}{|c|}{ B. Rates of Increase (per year, per 1,000) } \\
\hline 12. & $1750-1800$ & 4.3 & 4.2 & 4.3 & 9.6 & 0.9 \\
\hline 13. & $1800-1850$ & 5.1 & 6.7 & 4.5 & 5.2 & 3.5 \\
\hline 14. & $1850-1900$ & 5.4 & 10.6 & 3.3 & 0.3 & 5.6 \\
\hline 15. & $1900-1950$ & 8.4 & 8.1 & 8.3 & 4.9 & 10.7 \\
\hline 16. & $1950-75$ & 18.6 & 11.2 & 22.0 & 16.4 & 24.7 \\
\hline 17. & $1900-1920$ & 6.0 & 8.1 & 4.9 & 4.4 & 5.2 \\
\hline 18. & $1920-30$ & 10.8 & 12.0 & 10.0 & 5.3 & 13.0 \\
\hline 19. & $1930-40$ & 10.4 & 8.0 & 11.8 & 6.0 & 15.2 \\
\hline 20. & $1940-50$ & 9.2 & 4.4 & 11.8 & 5.5 & 15.3 \\
\hline 21. & $1950-60$ & 17.7 & 13.0 & 20.0 & 15.1 & 22.5 \\
\hline 22. & $1950-60$ & 17.9 & 13.1 & 20.3 & 16.0 & 22.5 \\
\hline 23. & $1960-70$ & 19.2 & 10.6 & 23.1 & 16.7 & 26.1 \\
\hline 24. & $1970-75$ & 19.0 & 8.7 & 23.3 & 16.5 & 26.3 \\
\hline
\end{tabular}

Notes

MDCs include Europe, the USSR, North America, temperate South America (Argentina, Uruguay, Chile), Australia, and New Zealand. LDCs include all others. Lines 1-4: from United Nations, The Population Debate: Dimensions and Perspectives, vol. 1 (New York 1975), table 1, pp. 3-4, and the original paper by John Durand cited there. The estimates for China used here are from the Durand paper. Lines 5-9a: United Nations, World Population Prospects (New York, 1966), table A.3.1, p. 133 .

Lines 8b-11: United Nations, Selected World Demographic Indicators, 1950-2000, mimeographed working paper ESA/P/WP.55, May 1975.

Lines 12-16: Calculated from lines $1-4,8 b$, and 11 .

Lines 17-21: Calculated from lines 5-9a.

Lines 22-24: Calculated from lines $8 b-11$. 
8.2. Part of this table refers to observed changes, to $1970-75 ; 2$ the other part refers to projections to the year 2000 . We deal with the observed changes first.

Between 1937 and $1970-75$, a span of about 35 to 36 years, the rise in the rate of natural increase for LDCs (excluding China) from 11.7 to 26.1 , some 14.4 points, resulted from a combination of a decline in the crude death rate from 30.8 to $16.0,14.8$ points, and a drop in the birthrate of only 0.4 points. A similar dominance of the drop in the death rate as the overwhelming factor in the rise in the rate of natural increase over the period from 1937 to $1970-75$ is also true of LDCs including China (for both comparisons see lines 15-20, cols. 2 and 5). By contrast, whatever movements occurred in the rate of natural increase in the MDCs have been due at least as much to declines in birthrates as to declines in death rates (see lines 12-14, cols. 2 and 5).

It is interesting to estimate the trend were we to extend the view to 1920 , the date that is the dividing line before the acceleration in the growth rate of LDC populations. In line 17 of table 8.1 we observe that the growth rate for LDCs for 1900-1920 was about $0.5 \%$ per year, meaning a rate of natural increase of 5.0 per 1,000. Assuming that the crude birthrate in 1900-1920 averaged about the same as in 1937 (42.5 per 1,000 ), we would obtain an implicit crude death rate (CDR) for 1900-1920 of 37.5 per thousand-compared with a CDR in 1937 between 31 and 32 per 1,000. If we assume that the recent downward trend in the crude death rate for the LDCs did not begin until the 1920s, the conclusion is that over a decade to a decade and a half before 1937, the drop in the CDR for LDCs was about 6 to 7 points per 1,000-of the same order of magnitude found in the somewhat longer periods from 1937 to $1950-55$, and from 1950-55 to $1970-75$ (see line 19 , cols. 2 and 4). And while the calculation is obviously approximate, it is reasonable to conclude that the estimated decline in the crude death rates was most likely much greater over that period than any reasonably assumed change in birthrates. ${ }^{3}$

Using the evidence in table 8.2, and the approximate calculations in the text, one may summarize by saying that over the fifty years terminating in 1970-75, that is, between 1920-25 and 1970-75, crude death rates in the LDCs must have declined from more than 37.5 to between 14 and 16 per 1,000 (see table 8.2, lines 16 and 19, col. 5); whereas the crude birthrates may have moved from 42.5 per 1,000 to either 42.1 (LDCs excluding China) or 37.5 (LDCs including China). The drop over the five decades was thus about 22.5 points in the crude death rate, and between 0.4 and 5 points in the crude birthrate-the rise in the rate of natural increase almost completely dominated by the downtrend in the death rate.

Several aspects of this recent decline in death rates in the LDCs should be noted. These and other aspects of what appeared to be the 
A. Absolute Totals and Growth Rates

$\begin{array}{lllll}1937 & 1955 & 1975 & 1985 & 2000 \\ (1) & (2) & (3) & (4) & (5)\end{array}$

\section{Total (in millions)}

$\begin{array}{lrrrrr}\text { 1. World } & 2,225 & 2,722 & 3,967 & 4,816 & 6,253 \\ \text { 2. MDCs } & 802 & 915 & 1,132 & 1,231 & 1,361 \\ \text { 3. LDCs } & 1,423 & 1,808 & 2,835 & 3,585 & 4,893 \\ \text { 4. LDCs, except China } & 899 & 1,203 & 1,997 & 2,612 & 3,745\end{array}$

Rates of Increase (per year, per 1,000, successive intervals)
5. World
$\begin{array}{llll}11.3 & 19.0 & 18.6 & 17.6\end{array}$
6. MDCs
$\begin{array}{llll}7.4 & 10.7 & 8.4 & 6.7\end{array}$
7. LDCs
$\begin{array}{llll}13.4 & 22.7 & 23.8 & 21.4\end{array}$
8. LDCs except China

$\begin{array}{llll}16.3 & 25.7 & 27.2 & 24.3\end{array}$

B. Vital Rates, Levels, and Changes

\begin{tabular}{llllllll}
\multicolumn{1}{l}{} & \multicolumn{1}{c}{ Change to } \\
1937 & Change to & $1950-$ Change to & $1970-$ & $1995-$ & $1995-$ Total \\
(1) $(2)$ & 55 & $1970-75$ & 75 & 2000 & 2000 & Change \\
& $(3)$ & (4) & (5) & (6) & (7) & (8)
\end{tabular}

World

$\begin{array}{ll}35.8 & -0.2\end{array}$

$35.6-4.1$

$31.5-6.4$

$25.1-10.7$

10. CDR

$25.7-6.9$

$18.8-6.0$

12.8

$-3.9$

$8.9-16.8$

11. CRNI

$10.1+6.7$

$16.8+1.9$

$18.7-2.5$

$16.2+6.1$

\section{$M D C s$}

12. $\mathrm{CBR}$

13. CDR

$24.1-1.2$

$22.9 \quad-5.7$

$\begin{array}{lll}-1.6 & 15.6 & -8.5\end{array}$

14. CRNI

$15.5-5.4$

$10.1-0.9$

9.2

$+0.7$

$9.9-5.6$

\section{$\angle D C s$}

\begin{tabular}{lrlllllrr} 
15. CBR & 42.5 & -0.4 & 42.1 & -4.6 & 37.5 & -9.7 & 27.8 & -14.7 \\
16. CDR & 31.6 & -8.3 & 23.3 & -9.0 & 14.3 & -5.7 & 8.6 & -23.0 \\
17. CRNI & 10.9 & +7.9 & 18.8 & +4.4 & 23.2 & -4.0 & 19.2 & +8.3 \\
LDCs except China & & & & & & & \\
18. CBR & 42.5 & +2.0 & 44.5 & -2.4 & 42.1 & -11.3 & 30.8 & -11.7 \\
19. CDR & 30.8 & -6.4 & 24.4 & -8.4 & 16.0 & -7.1 & 8.9 & -21.9 \\
20. CRNI & 11.7 & +8.4 & 20.1 & +6.0 & 26.1 & -4.2 & 21.9 & +10.2 \\
\hline
\end{tabular}

\section{Notes}

Panel A: The estimates for 1937, lines 1-4, col. 1, are logarithmic interpolations between the totals for 1930 and 1940 shown in lines 6-7 of table 8.1. The other entries in lines 1-4 are from the source used for table 8.1 , lines $8 b-11$, with the use of the medium variant projection throughout.

The rates of increase in lines 5-8 are from lines 1-4, with due allowance for the varying durations of the intervals (which are 18,20,10, and 15 years respectively). Panel B:

Col. 1: Data from United Nations, World Population Trends, 1920-1947 (New York, 1949); table 2, p. 10, shows the vital rates, and we took the mid-value of 
major demographic revolution in world population have been widely discussed in the literature; $;^{4}$ but they deserve at least brief explicit mention here.

The first aspect of the recent declines in death rates in the LDCs is that they proceeded at a rate far exceeding that of the past declines in death rates in the currently developed countries. Table 8.3 illustrates the contrast with the older European countries. A drop of 22.5 points in the rates in the LDCs over five decades meant a decline per decade of 4.5 points. For the five northern European countries, the rates of decline per decade were, for the successive intervals in columns 5-7, 0.76, 0.84, and 1.80. For the other four European countries, the declines per decade in the death rates were 1.11 points for the interval $1850-95$, and 2.10 for the interval 1895-1925. If the initial position of the LDCs in 1920-25 is compared with that of the European countries either in 1800 or in 1850 , the rate of decline in the LDCs over the first five decades of their demographic transition was from four to five times as high as that for the older, settled, currently developed European countries.

One should also note that, in the earlier phases of the shift in demographic patterns, the movements of the birthrates in the currently developed countries were also at rates much lower than those in the death rates-so that the initial rises in the crude rates of natural increase were, as in the case of the recent trends for the LDCs, due predominantly to the declines in mortality.

The second distinctive feature of the recent major drop in death rates in the LDCs is that it occurred in regions where the basic economic and institutional structures were little affected by industrialization and modernization - whereas the trends in death rates that we observed for the currently developed countries in table 8.3 occurred largely in association with marked upward movements in per capita product and, more important, advances of the countries in the economic and institutional transformation associated with modern economic growth. This was certainly true beginning with the mid-nineteenth century. And, one should add, both the rapidity of the recent decline in death rates in the LDCs and its occurrence without association, in many of the regions involved, with any significant economic and institutional changes, can be credited to

the ranges shown. MDCs here include North America, Japan, Europe, and Oceania (but exclude temperate South America, a minor omission here and a minor inclusion under the LDCs). China is identified with "Remaining Far East" (after exclusion of Japan). The population weights used to combine the rates are in the source, table 1, p. 3.

Cols. 2-8: Based on data from the United Nations working paper used for lines $8 b-11$ of table 8.1 (on Selected World Demographic Indicators by Countries, 1950-2000). 
Table 8.3

Long-term Trends in Crude Vital Rates (per 1,000), Currently Developed Countries (for Comparison with Recent Trends in the LDCs)

\begin{tabular}{|c|c|c|c|c|c|c|c|}
\hline & \multicolumn{4}{|c|}{ Levels of Vital Rates } & \multicolumn{3}{|c|}{ Changes in Rates } \\
\hline & $\begin{array}{l}1800 \\
\text { (1) }\end{array}$ & $\begin{array}{l}1850 \\
(2)\end{array}$ & $\begin{array}{l}1895 \\
(3)\end{array}$ & $\begin{array}{l}1925 \\
(4)\end{array}$ & $\begin{array}{l}1800-1850 \\
(5)\end{array}$ & $\begin{array}{l}1850-95 \\
(6)\end{array}$ & $\begin{array}{l}1895-1925 \\
(7)\end{array}$ \\
\hline \multicolumn{8}{|c|}{ Five Northern European Countries } \\
\hline 1. CBR & 34.0 & 32.8 & 29.8 & 20.6 & -1.2 & -3.0 & -9.2 \\
\hline 2. $\mathrm{CDR}$ & 25.2 & 21.4 & 17.6 & 12.2 & -3.8 & -3.8 & -5.4 \\
\hline 3. $\mathrm{CRNI}$ & 8.8 & 11.4 & 12.2 & 8.4 & +2.6 & +0.8 & -3.8 \\
\hline \multicolumn{8}{|c|}{ Four Other European Countries } \\
\hline 4. $\mathrm{CBR}$ & n.a. & 31.5 & 30.0 & 21.2 & n.a. & -1.5 & -8.8 \\
\hline 5. $\mathrm{CDR}$ & n.a. & 25.0 & 20.0 & 13.7 & n.a. & -5.0 & -6.3 \\
\hline 6. CRNI & n.a. & 6.5 & 10.0 & 7.5 & n.a. & +3.5 & -2.5 \\
\hline
\end{tabular}

Notes

The averages in lines $1-6$ are calculated from the vital rates summarized in Simon Kuznets, Modern Economic Growth (New Haven: Yale University Press, 1966), table 2.3, pp. 42-44. Lines 1-3 include England and Wales, Denmark, Finland, Norway and Sweden; lines 4-6 include Belgium, France, Germany, and the Netherlands. For all countrics the year indicated represents the midpoint of a long interval over which the crude rates were averaged, the interval varying between sixty, forty, and ten years. The entries represent unweighted arithmetic means of the values for the individual countries included.

The changes in columns 5-7 are derived directly from the averages in columns $1-4$.

the nature of the technological revolution in dealing with infectious diseases and with the major health problems of the LDCs, which apparently began after World War I and attained its most striking successes shortly after World War II.

Third, granted the importance of major innovations in the technology related to control of diseases and of mortality, and the pervasive spread of declines in mortality to LDC regions and countries differing widely in institutional and economic structure, complementary effects of other technologies were required and differences in exposure to modernizing influences continued to affcct death rates. After all, the new medical and public health tools had to be made accessible to all population groups in the LDCs to produce the wide effects observed (see comment below); here the technological revolution in transport and communication played an important role. And differences in extent and duration of exposure to modernizing influences are reflected even now in death rate differentials among major groups of LDCs (and would be even more prominent in single-country comparisons). Thus, table 8.4 below shows that, even by 1970-75, crude death rates in sub-Saharan Africa (excluding the 
southern region) were, at 22 per 1,000, more than twice as high as those for Latin America (excluding the Temperate Zone) at somewhat over 9 per 1,000 .

Finally, one should note that declines in death rates (as in other vital rates) of the magnitude suggested for the LDCs over the last fifty years -and perhaps even for each of the quarter-century subperiods separately-mean that the demographic trends involved must have necessarily affected large proportions of the total population involved. For each of these vital rates is a weighted average of group-specific rates, weighted by the groups' proportions in the total. Thus, a decline in the crude death rate of a few points, say from 32 to 30 per 1,000 , could well be accounted for by a decline of 6 points for a group whose mortality declined from 32 to 26 per 1,000 while that of the remaining group stayed constant-the two groups accounting for one-third and two-thirds of the total population respectively. But a much larger decline, and conditions in which the death rate of a small group in the total population cannot be sharply reduced while mortality remains high in the rest of the population, mean that the impact of the decline must necessarily have been widespread. This point is of analytical importance, considering the contrast between the sharp downtrends in the death rates and the minor declines in birthrates-with implications for the possible differential effects of the two sets of trends on the various groups in the population, particularly the smaller economic and social groups at the top and the much larger proportions of the population at middle and below-average economic and social levels.

In turning now to the sections of table 8.2 that relate to population and vital rate projections to the year 2000 , we may view the latter as informed judgments of the likely demographic trends--on the assumption that no great catastrophes or miraculous boons introduce major discontinuities, and the more interesting assumption that economic and social progress will take place at a feasible pace to warrant expectation that the growing populations will be sustained at acceptable levels. ${ }^{5}$ From our standpoint, the major interest in these projections is their indication that while the growth rates and the vital rates in the developed countries will move slowly downward over the last quarter of this century-and show no declines in the death rates-for LDCs (excluding China) death rates will still decline substantially (see line 19, col. 6). And while the birthrates for the LDCs are assumed to drop even more (see line 18, col. 6), the projections for the last quinquennium still show a rate of natural increase over $2 \%$ per year and well above the initial rates either in 1937 or even in 1950-55.

But given the large magnitudes of, and some significant disparities within, the total of LDCs, it is useful to consider the magnitudes and projections separately for the major LDC regions-and with some time 
break from 1950-75 to 1995-2000 (table 8.4). The total LDC population for 1975 accounted for in this table can be compared with that in table 8.2, for LDCs excluding China-and it is 1,918 million compared with 1,997 in line 4 , column 3 of table 8.2.

One should begin by noting the dominance of the South Asian region in the 1975 total, and the Asian contribution would become all the larger were we to include China. In 1975, the population for China implicit in table 8.2 is 838 million. Of the total for South Asia, the contribution of what might be called the clearly Hindic group (Bangladesh, Pakistan, and India) was 758 million. Thus, of the total in 1975 of the four regions shown in table 8.3 plus China-2,746 million--as much as 1,596 million was accounted for by the two areas that could be designated centers of the centuries-old Sinic and Hindic civilizations. Of the total additions over the twenty-five year period from 1975 onward-some 1,984 million-310 million are projected for China (see table 8.2) and another 593 million for the three Indian countries listed above. Thus, by the year 2000 , the areas that are the centers of these two old civilizations would still account for 1,148 plus 1,351 billion, or a total of some 2.5 billion out of an aggregate of 4.74 billion for all LDCs in the four regions plus China. The emphasis on this large contribution of these two old civilizations to the population bulk, and to current and projected excess growth of the LDCs, points to a consideration of the past economic and social innovations that permitted the sustained growth of this population mass on an area far smaller than that occupied by the other LDCs-innovations in agriculture and institutional devices. These would presumably affect the responses of the relevant populations to the declines in the death rates and to the changing role of the next generation in the adjustment to widening economic opportunities associated with industrialization and modernization."

There were marked differences among the regions in the levels of death rates in 1950-55, the earliest quinquennium for which the comparison is easily made. In Latin America, these death rates were as low as 15.2, as result of preceding declines that proceeded at a slow pace to the 1930s and accelerated thereafter (Arriaga and Davis 1969). In the same quinquennium, the crude death rates ranged from 22.5 to 28.5 per 1,000 in the three other LDC regions. With the crude birthrates at roughly similar levels, the result was a substantial range in rates of natural increase, from 19 to 28.5 per 1,000 .

Over the twenty-five-year period to 1975 , there were substantial declines in the crude death rates in all four LDC regions, leaving the differentials in death rates in 1975 even wider, at least proportionally, than they were in 1950-55 (see col. 3, which shows a range of 9.3 for Latin America to 21.8 for sub-Saharan Africa), and the declines in death rates were substantially larger than the declines in birthrates, leading to a rise 


\begin{tabular}{llllllll} 
& & \multicolumn{1}{c}{ Change to } \\
$1950-$ & Change to & $1970-$ & Change to & $1980-1995-$ & $1995-$ Total \\
55 & $1970-75$ & 75 & $1980-85$ & 85 & 2000 & 2000 & Change \\
(1) & $(2)$ & (3) & (4) & (5) & $(6)$ & (7) & (8)
\end{tabular}

East and middle South Asia $(1,162 ; 2,093)$

$\begin{array}{lrrrrrrrr}\text { 1. CBR } & 44.1 & -2.2 & 41.9 & -3.5 & 38.4 & -10.2 & 28.2 & -15.9 \\ \text { 2. CDR } & 25.2 & -8.7 & 16.5 & -3.8 & 12.7 & -3.9 & 8.8 & -16.4 \\ \text { 3. CRNI } & 18.9 & +6.5 & 25.4 & +0.3 & 25.7 & -6.3 & 19.4 & +0.5\end{array}$

Middle East (186; 366)

$\begin{array}{lrrrrrrrr}\text { 4. CBR } & 47.1 & -4.0 & 43.1 & -2.4 & 40.7 & -9.1 & 31.6 & -15.5 \\ \text { 5. CDR } & 22.4 & -7.6 & 14.8 & -3.1 & 11.7 & -3.8 & 7.9 & -14.5 \\ \text { 6. CRNI } & 24.7 & +3.6 & 28.3 & +0.7 & 29.0 & -5.3 & 23.7 & -1.0\end{array}$

Sub-Saharan Africa $(275 ; 566)$

$\begin{array}{llllllllr}\text { 7. CBR } & 48.7 & -1.1 & 47.6 & -1.0 & 46.6 & -4.7 & 41.9 & -6.8 \\ \text { 8. CDR } & 28.6 & -6.8 & 21.8 & -3.6 & 18.2 & -5.4 & 12.8 & -15.8 \\ \text { 9. CRNI } & 20.1 & +5.7 & 25.8 & +2.6 & 28.4 & +0.7 & 29.1 & +9.0\end{array}$

Latin America, except temperate zone $(285 ; 567)$

$\begin{array}{lrrrrrrrr}\text { 10. CBR } & 43.7 & -4.8 & 38.9 & -2.3 & 36.6 & -6.0 & 30.6 & -13.1 \\ \text { 11. CDR } & 15.2 & -6.0 & 9.2 & -2.0 & 7.2 & -1.9 & 5.3 & -9.9 \\ \text { 12. CRNI } & 28.5 & +1.2 & 29.7 & -0.3 & 29.4 & -4.1 & 25.3 & -3.2\end{array}$

LDCs, four regions above $(1,908 ; 3,592)$

\begin{tabular}{lrrrrrrrr} 
13. CBR & 45.0 & -2.6 & 42.4 & -2.8 & 39.6 & -8.7 & 30.9 & -14.1 \\
14. CDR & 23.9 & -7.9 & 16.0 & -3.4 & 12.6 & -3.8 & 8.8 & -15.1 \\
15. CRNI & 21.1 & +5.3 & 26.4 & +0.6 & 27.0 & -4.9 & 22.1 & +1.0 \\
\hline
\end{tabular}

Notes:

The underlying data are all from the United Nations working paper cited in the notes to tables 8.1 and 8.2 .

The totals entered in parentheses following the dcsignation of rcgions are the 1975 and year 2000 populations of the region, in millions.

East and middle South Asia is a combination of east South Asia and middle South Asia. The internal weights, based on the 1975 population, are 3 and 7 for the two subregions respectively.

Middle East comprises western South Asia and North Africa, with approximately equal weights.

Sub-Saharan Africa includes three subregions-eastern Africa, middle Africa, and western Africa (with approximate weights of 4, 2, and 4). Southern Africa was omitted because of the weight in it of the Union of South Africa and the mixed composition of its population with different levels of economic development.

Latin America comprises the Caribbean, Middle Amcrica, and Tropical South America, with approximate weights of 1,3 , and 6 . The Temperate Zone (Argentina, Uruguay, and Chile) was omitted.

The total of LDCs is a weighted average of the four regions (with weights of $60,10,15$, and 15 , for the regions in the order listed).

For more detail concerning inclusion of individual countries, sce the source. China and East Asia, in general, are omitted, and so are some LDCs in Oceania. 
in the rate of natural increase in all four regions. Yet for Latin America, the region furthest along in the demographic transition, the decline in birthrates was more substantial and the rise in rates of natural increase rather minor. The result was that by 1975 the regional differentials in rates of natural increase were narrow (from 25.5 to 29.5) - the rates being at relatively high levels in all four regions.

But the most interesting part of table 8.4 is the indication that for three of the four regions, excluding Latin America, the next decade, to the mid-1980s, will again show greater declines in death rates than in birthrates-with consequent further rises, even though minor, in the rates of natural increase. It is only in the period after the mid-1980s that the birthrates are expected to decline substantially enough to exceed the still-expected further declines in the death rates. Even so, one region - sub-Saharan Africa-is, according to the present projections, to show rising rates of natural increase practically to the end of the century.

Further subdivisions within the regions would reveal even further differences among various groups of the LDCs in the levels of their vital rates, and distinction of narrower time periods would more clearly reveal differences in past and projected changes in these basic demographic trends. Thus, the differences among the currently distinguished four regions with respect to the timing in the demographic transition-from Latin America as the most advanced to sub-Saharan Africa as the least - would be refined further; and so would the difference in timing in reaching the peak rate of natural increase, and the peaks and troughs in the underlying birthrates and death rates. But the distinctions in table 8.4 are sufficient to indicate both the similarities and the major differences in the movements of the death rates, in their relation to the levels and changes in the birthrates; and to remind us of the diversity of the demographic, and implicitly economic and institutional patterns, among the major groups within the LDC universe. The recognition of this diversity is particularly important, as we shift now to an exploration of the possible implications these movements in death rates, in their relation to those in birthrates, have for the internal economic distributions in the countries affected.

\subsection{Some Implications}

What were the likely effects of the recent population trends in the LDCs, summarized in the preceding section? In attempting to formulate some speculative but plausible answers to this question, it seemed best to start with $(a)$ the effects of the rapid and striking declines in the death rates; and then turn to $(b)$ the possible reasons for the lag in the declines of the birthrates. The separation between the two trends 
may seem artificial; and yet I will argue below that the choices with respect to the downward movement of death rates were more limited than those with respect to the adaptive movement of birthrates. If only for this reason, one is warranted in considering the two sets of trends separately before attempting to combine their possible effects.

\subsubsection{Declines in Death Rates}

In dealing with the effects of the recent major declines in mortality in the LDCs, we may ask first what kind of demographic patterns prevailed in these countries before, when high death rates and birthrates yielded low rates of natural increase. Were there substantial withincountry differences among the various economic and social groups, in demographic structure and in the rates of natural increase?

No adequate direct evidence on this question is available to me, although a long search in the literature and greater familiarity with the sources might have provided it. But some plausible conjectures can be suggested. First, in these pre-1920 decades, as table 8.1 indicated, the MDCs were characterized by markedly lower death rates than the LDCs, so that the rate of natural increase in the former was substantially higher - despite the fact that their birthrates were substantially lower. This suggests that, with death rates in the LDCs at these high levels, even a moderate proportional lowering of the death rate could allow for a moderate decrease in the birthrate and still result in a substantial rise in the rate of natural increase. With CDR at, say, 40 and a CBR at 45 , a drop in the former to 36 and in the latter to 42 would mean a rise in the rate of natural increase to 6 per 1,000—-by a full fifth. One may reasonably assume that also within the LDC country or region there could have been differences among economic and social groups, where greater wealth and easier access to means of subsistence could have resulted in appreciably lower death rates-and, even if these led to somewhat lower fertility, the more favored economic of social groups might have attained a higher rate of natural increase-just as the MDCs did in the comparison with the LDCs. This would be particularly likely so long as higher economic and social status was not connected with greater health risks in urban conditions (if urban living was a prerequisite of higher income). But in the countries and times of which we are speaking, urban populations constituted a minor fraction of total population. ${ }^{\top}$

The implication is that in the earlier decades of high levels of both mortality and fertility, before 1920, differences within the LDCs in economic and social status may have been associated with reductions in mortality that were substantial and larger than the likely restraints on fertility (if any) - thus yielding a higher rate of natural increase among the upper social and economic groups than among the lower ones. If this implication is valid, the resulting contrast with the conditions in times 
and countries in which the overall level of death rates has been reduced sufficiently so that large relative mortality differentials could not convert even minor birthrate excesses into equality or shortage of the rates of natural increase, is of major analytical importance.

Unfortunately, I can find only illustrative evidence, relating primarily to differentials in death rates in one or two less developed countries by economic or social status (directly given, or associated with some ethnic group distinctions), or separate evidence on birthrates by social status or ethnic grouping-but not the two bodies of evidence together. Thus, to cite an example for India, in 1931 the expectation of life at birth for Parsis was (combined with equal weight for men and women) as high as 53 years-compared with 32 years for total population-and the difference is "attributed in large measure to the relatively advantageous position of the Parsis" (United Nations 1953, p. 63). If we apply crude conversion ratios to expectation of life at birth to derive crude death rates as used by Kingsley Davis (that is, setting the latter to 1,000 divided by expectation of life), ${ }^{8}$ the corresponding CDRs are 19 per 1,000 for the Parsis (a small group in the large total) compared with more than 31 per 1,000 for total population-a difference that may or may not have been fully compensated by the difference in crude birthrates. Similar evidence of substantial differences in death rates appear in the summary of a sample survey of rural families in Punjab in 1931. One may note that in the 1973 edition of United Nations, The Determinants ..., the relevant section on mortality differentials in less developed countries (par. 132, p. 139) begins with a statement that information on these "differentials by occupation, income, and education is . . sparse" and quotes only a few cases, mostly for the late 1950 s or early 1960 s.

A related illustration of interest can be derived from the vital rates for the United States when the distinction is made between the white population and the nonwhite (the latter predominantly Negro). For 1905-10 (the earliest period for which the comparison is given) the gross reproduction rate was shown at 1,740 for the white population and 2,240 for the nonwhite-an excess of the latter of some $30 \%$; but the net reproduction rate, that is, the one that takes account of mortality, was 1,339 for the white population and 1,329, somewhat lower, for the nonwhite population. This is an illustration of greater mortality in the economically and socially disadvantaged group more than offsetting a much higher fertility; and it is shown for a period when crude death rates averaged (for 1900-1904) 16 per 1,000 for the white population and about 26 per 1,000 for the nonwhite. ${ }^{9}$ It is plausible to assume that further back in time, when the level of death rates was appreciably higher, their excess may have produced an even greater differential in rate of natural increase in favor of the white population. By contrast, 
in the later period, when death rates declined for both white and nonwhite populations, the net reproduction rate of the nonwhite population began to exceed that of the white by a large margin. Thus, by 1957 (the peak year in the United States reproduction rates in recent times) the gross rate of the nonwhite population, at 2,371, exceeded that of the white, at 1,764 , by almost $40 \%$; the net rates were 2,206 and 1,701 respectively, an excess of almost $30 \%$.

Finally, one should note briefly the data on demography of peasant communities. ${ }^{10}$ They deal largely with fertility, strongly suggesting, though with some exceptions, that fertility is higher among the richer (in terms of land) peasants than among the poorer; with mortality, at least in children, also being distinctly lower among the rich. The result, then, is a positive association within the peasantry between higher economic position and rate of natural increase. But the findings are qualified by sparsity of coverage, particularly for LDCs in the premodern periods of high mortality; the limitation of the data largely to fertility; the absence of data on per capita income of the peasant families classified by size over the life cycle; and the difficulty of assigning weights to the peasant population (distinctly smaller than the rural) within the total. A further exploration of the field, not feasible here, may yield significant findings.

If we assume that the rate of natural increase within the LDCs, before the recent sharp decline in death rates, was greater among the upper economic and social groups, the situation would have been in sharp contrast to that in the MDCs for a number of decades and that in the LDCs once overall death rate levels have been substantially reduced. The more familiar finding is that the birthrates and the rates of natural increase have been greater among the lower income groups-associated with the greater lag in the declines of birthrates among the former, in conditions under which a generally lower level of death rates reduced the weight of the death variable in offsetting births. This also meant that in the earlier times in the LDCs, the number of surviving children per family - once it reached a decade or more beyond the marriage datewas greater among the upper economic and social groups than among the lower, with the necessary qualification concerning the urban death rate excess over the rural. Since the number of surviving children is in turn a major factor in determining the size of the family (the other being the degree of "jointness"), it is possible that the average sizc of the family was larger among the upper than among the lower economic and social groups; and that the average income of this larger family, even on a per capita basis, was significantly greater than that of the smaller family among the lower economic and social groups. Such positive association between the size of family and per capita income is not found in recent cross-sectional studies, which are naturally limited either 
to MDCs or to LDCs with death rates already substantially reduced by recent advances in health technology. On the contrary, the negative association between size of family or household and its per capita income is a common finding; and while qualified by changes in income levels over the life cycle, still remained a major result in the analysis in the recent paper cited in note 1 (see section III, pp. 23-48, on the size of family or household effects).

But more important here is the implication that this situation of higher death rates and lower rates of natural increase among the lower economic and social groups meant a serious aggravation of already existing inequalities, in that shorter life-spans, greater morbidity, and fewer children surviving to productive ages were both cause and effect of lower economic returns over the family's productive life-span. This association of lower economic position with higher rates of death and morbidity persisted, of course, beyond the transition in the population patterns from premodern to modern times; and it is still found in the MDCs in recent decades. But the effects of this association must have been far greater when death and morbidity rates were so high, and when substantial reductions in them could be attained by more food, better clothing and sheltcr, and greater mobility for protection against epidemics or famines. Of course, we cannot now gauge these differentials in death rate and rate of natural increase or test their persistence in conditions of frequent short-term rises in death rates that might have swept over rich and poor alike. But one may assume that if there were these death and natural increase differentials in the pre-modern LDCs, they served only to aggravate long-term economic inequalities rather than to temper them.

In this connection, the exploratory illustration of economic losses represented by the deaths of children and young adults in the Appendix to this paper is of interest. These explorations compare the losses of past inputs into children and young adults (the latter dying before their net contribution might have fully covered the past inputs into their consumption ), in a less developed and a developed country in the 1930srelating these annual losses to the total annual product of each of the two countries. The results of the comparison, indicating that relative losses involved in such deaths are more than five times as great in the less developed as in the developed country, only suggest what might be found by comparing similar losses from deaths for the richer (lower mortality) and poorer (higher mortality) groups within a premodern LDC. Clearly, the burden of such losses was proportionally much greater among the lower-income groups, representing a greater relative drain on their long-term economic capacity and resources.

The comments above are meant to provide a tentative base for evaluating the effects of the striking declines in death rates that we find in the 
tables in section 8.1. Given their magnitude and the character of the major causal factors involved, it is reasonable to infer that these reductions in death rates were widespread; that their absolute magnitude was greater among those groups in the population for whom the initial levels were higher; and that consequently their effects on the rates of natural increase were far greater for those groups in the population for whom these rates were initially lower-the larger groups at the lower economic and social levels. If the death rates for the upper and lower groups could differ by as much as 10 points (e.g., 30 to 40 ), it could be expected that a major step forward in health care and medical technology applicable without a major input of scarce resources and without requiring major changes in patterns of life would affect the higher death rates absolutely more than it would affect the lower death rates already reduced by more favorable economic conditions in the past. And one could also argue that the benefit would be greater to those who have sustained the losses caused by higher death rates in the past. The immediate implication, subject to a major qualification noted below, is that the differential reduction in death rates plausibly assumed above, the resulting convergence of internal death rates among various economic and social groups, meant the reduction of an important aspect of persisting inequality that loomed large in the premodern LDC societies.

Before we consider the possible qualification on the equalizing effects of the internal differentials in reduction of death rates in the LDCs once the major declines began, we should stress two aspects of the trends under discussion. The first, already noted, is that little choice was possible, or wanted, in incurring these declines. If they came, largely as effects of developments in the MDCs brought into the LDCs from the outside, as it were, relicving sickness and death without incurring perceptible economic and social costs, there was no incentive for resisting the much-desired opportunity for longer and healthier life. In that sense the situation was quite different from the choices relating to birthrates: reducing these involved a variety of alternatives within limits that could spell substantial differences in population growth rates, for countries or for groups within them. Second, and more important, once contacts with the developed parts of thc world were increasingly numerous, it became obvious that the reduction in death rates (and associated reduction in rates of morbidity) was a necessary if not sufficient requirement for a healthier, long-lived, population-with the possibility of longer investment in the training and education of the younger generation preserved from demographic calamities, with the chances of developing a forward spirit in a population justifiably believing in man's control over his destiny, and with a family structure in which smaller size and fewer children would make possible a better adjustment to widening economic 
and social opportunities. Rejecting the contacts that reduced the death rates would thus mean also rejecting the possibility of shifting to a modern demographic pattern and modernization of society that could also mean better use of the potentials of economic growth. ${ }^{11}$

The conclusion is that the reduction of the death rates in the LDCs from their initial high levels in the 1920s was an indispensable condition for eventual modernization and participation in modern economic growth-while the rapidity and magnitudes of the declines were unavoidable (were anybody willing to avoid it) effects of the new technology in situations of a backlog of high mortality and high morbidity problems. Whatever the immediate, or shorter-term, consequences of these trends, particularly those when the failure of birthrates to decline resulted in a rapid acceleration of the rates of natural increase, in the longer run the major declines in death rates were a precondition of the declines in birthrates and of other adjustments to the modern demographic patterns of population growth.

The major qualification alluded to above is, of course, the consequence of lag of the decline in birthrates-in conditions where the basic innovation introduced by the reduction in death rates was not accompanied by sufficient changes in other aspects of social and material technology. In such conditions, and provided there was-as there was likely to be with stagnant social structure and production technologyscarcity of the traditional resources (whether land or reproducible capital), a rapid acceleration of rates of natural increase among the groups hitherto below the upper economic and social levels may have meant suddenly increased pressures of augmented labor supplies on scarce complementary resources. Whether under these conditions a longer and healthier working life of the members of a family compensated, over the life cycle, for the greater pressure of labor on resources is a question that does not admit of an easy answer; and the answer would vary among various groups of LDCs, depending upon the initial resource endowments and the degree to which further advances in traditional technology were possible with augmented labor. Here the added knowledge concerning the demographic and economic structures of LDCs before the recent declines in death rates would be required to provide even tentative answers. But one cannot exclude the possibility that in some cases the longer productive life-span and greater increase of the lower economic and social groups may still have resulted in some widening of internal income inequality because upper groups took advantage of the greater pressure of labor on land or on other capital, while in other cases the inequality-reducing internal convergence of rates of mortality and morbidity among the several economic groups might have reduced internal income inequality-even if the crude birthrates con- 
tinued at high levels and failed for some time to respond to the declines in death rates.

On this uncertain conclusion, I end the discussion of the effects of declines in mortality in the LDCs. One should emphasize to the end the indispensable - and in the longer run beneficial-effects of the declines in the death rates, regardless of whether their immediate and direct effect was to widen or to narrow internal income inequalities. This emphasis might have been superfluous except that much recent discussion of the problems created by rapid population growth tends to neglect the source of the latter in the declines in mortality and morbidity-and thus to understate, by omission, their vitally important and beneficial long-term effects. ${ }^{12}$

\subsubsection{Lags in the Decline of Birthrates}

The long lag in fertility decline behind the downtrend in mortality is illustrated in Professor Lindert's paper for this conference, on "Child Costs and Economic Development" (chap. 1) and is strongly suggested for the LDCs in the initial section of this paper, with its emphasis on the dominance of declines in mortality in contribution to a rising rate of natural increase in the face of constant or only slightly dropping birthrates. This section deals with a few aspects of the response of birthrates to the major declines in death rates in the LDCs.

Even though the would-be parental pair is the immediate decision unit in this response, one must allow for the wider, blood-related groups (an extended family, a tribe, an ethnic group, a caste) that may set the norms for the would-be parents. In addition, there are the large nonblood collectives, particularly the government, that may react to declining death rates and accelerating population growth in a variety of ways, all of which involve modifications of conditions under which the family unit would make decisions concerning more or fewer children-whether the steps are limited to exhortation and to providing cheaper methods of birth control or extend to drastic policy measures affecting the costs of more children. On the other hand, the effects of declining deaths include more than just increase in numbers of surviving children. The underlying innovation in health and medical technology may reduce involuntary sterility formerly associated with widely prevalent debilitating diseases; it may raise intramarital fertility by prolonging the duration of marriage (within the childbearing span of the wife) through the reduction of mortality (particularly male) in the procreative ages-just as it may eventually, by reducing uncontrollable and unpredictable diseases, introduce changes in would-be parents' outlook on the future and the role of the next generation. Given the diversity of possible sources of decisions in response to declining death rates, the variety of direct and indirect effects of the latter on the birthrate response, and finally 
our inadequate knowledge of the parameters of demographic processes and of economic and institutional patterns in various LDC regions, we can attempt only a limited probing.

This is true even if we eliminate from consideration the communist societies, in which the power of the single-party, ideologically motivated government is such that its responses to declining death rates and accelerating population growth may dominate whatever free responses could have originated within the population masses of the country. Such domination is suggested by the power of intensive propaganda, control over location and migration of the population, disposition of the basic consumer goods, particularly housing, needed for a growing population, and the like. I would find it difficult, for lack of adequate knowledge of societies so organized, to formulate a rational basis for evaluating the planned response that the governmental decision centers of these countries would make to declining death rates and rising rates of natural increase. The same criterion might also lead to exclusion of noncommunist, dictatorially organized LDCs, in which a similar domination of the state over the free responses of the population might be expected; but there are no clear relevant measures for drawing the line. The purpose of the comment is to call attention to the possible policy interventions of groups not related by blood, particularly those endowed with internal sovereignty. They may be important in both dictatorially and democratically organized societies; but their weight seems more dominant in the former-sufficiently so to warrant limiting further discussion by concentrating on the societies with relative freedom of decision by families and related blood groups.

The importance of the wider, blood-related groups that encompass the individual families is clearly great in LDCs, whether they be the tribal groupings in much of Africa, the racial-ethnic divisions within many Latin American countries, or the groupings in Asian countries where limited intermarriage among groups (say, among castes in India) is still the norm. In conditions of relative weakness and instability of the country's collective institutions, particularly the state, such wider blood-related groups serve an important function in providing long-term security to individual families in conditions of group competition. The response of a family to declining death rates and more surviving children would, with reference to the wider group norms, differ from that of an individual family within a stable political framework, relying securely on the protection and stability of a strong government representing the interests of the community and of all its parts. An adequate analysis would require taking specific account of these various blood-related subgroups within the populations of the several LDC regions in the process of their reaction to declines in death rates. But for obvious 
reasons our discussion can take only general cognizance of these sources of influence on the decisions of would-be parents.

We may now face a limited question. Assume that the individual families, the pairs of would-be parents, either experience or observe a perceptible reduction in death rates, both through the reduction of infant and child mortality and through declines in deaths of adults. Under what conditions would we expect a relatively prompt and full response of birthrates such as would prevent the rate of natural increase from rising substantially over a relatively long period? These conditions would presumably bear on (1) firmness of judgment with respect to continuity (irreversibility) of the observed declines in mortality; (2) the relation of the resulting numbers of surviving children to the desired numbers; and (3) the identity of the population group in a position to realize an effective birthrate response and the limits of their possible perception of mortality declines. ${ }^{13}$

1. Given the emergence of a marked downturn in death rates as a novel phenomenon for populations and countries that for centuries have experienced a much higher average mortality, and, most important, with instability characterized by sharp short-term declines and equally shortterm larger rises, a fairly long period of observation and experience at lower and stable death rates would be required before a response could be expected. This is particularly true at the later stages of the woman's childbearing span, when a decision to forego another child, in reliance on the persistence of low death rates for children, may be beyond repair if the expectation proves false. How long a period of waiting to test the persistence of the mortality trend one should reasonably assume would have to be estimated from an analytical case in which all other factors affecting the decision (except the decline in mortality itself) have been removed (i.e., held constant) - not an easy task. A span of well over a decade seems a minimum, and one could perhaps argue that, ruling out downward revisions in numbers of desired surviving children, a whole generation might have to pass before the next parental generation could react significantly. Yet, given the declines in crude death rates averaging between 4 and 5 points per 1,000 per decade over the last half-century (in the LDCs from the mid-1920s to the mid-1970s), a lag of only one decade would mean a substantial addition to the rate of natural increase -which would continue so long as the death rates continued to decline, even though persistence of the latter would, as time goes on, raise confidence and reduce the lag.

The judgment of confidence in the continuity and irreversibility of a new social trend is hardly susceptible of tests for either ex ante or post facto validity, and one hesitates to assign a large weight to it. Yet complete neglect of it implies a neglect of a possibly major problem of the channels by which effective perception of, and response to, new 
social processes is attained within the traditional, and later transitional, framework of LDCs. It may well be that a long delay in response to new trends is a rational reaction, due partly to limitation of information, partly to lack of resources for taking chances on uncertain trends and for overcoming the fear of the unknown.

2. The conjecture under (1) becomes less relevant if we can assume that over a long initial period of the decline in mortality in the LDCs, the desired number of surviving children remains higher than, or in the neighborhood of, the actual number (as perceived by the family). Given targets or norms, whether individually elaborated or more realistically set as norms in the form of socially approved patterns; whether hard or, more realistically, with soft margins, it is not difficult to see that beginning at the premodern levels of death rates and birthrates, there might be a long period of sustained mortality declines - and yet the resulting number of surviving children would remain short of or close to the desired target, thus providing no incentive for a response decline in birthrates.

To begin with, the declines in mortality and morbidity permit those groups in the population that formerly could not reach their fertility targets-either because of involuntary sterility or because of institutional constraints on remarriage of widows or because of other similar consequences of past mortality and morbidity-to start approximating them. Far more important, quantitatively, is the condition of the large economic and social groups below the narrowly defined top. Given the rather low rate of natural increase of LDCs just before the initiation of the recent downtrends in mortality (of about $0.5 \%$ in the $1920 \mathrm{~s}$ ), it is reasonable to suggest that for the majority of the population the number of surviving children was below the desired number. This suggestion is strengthened if we assume the earlier conjecture (discussed in section 8.2.1 above) that at the top economic and social levels in the premodern LDCs death rates and rates of natural increase were substantially lower and greater respectively than at the lower levels. For this would mean a long-persisting pattern of association of a much larger number of surviving children with the higher economic and social status, which would most likely be carried over into the initial decades of the declines of death rates in the LDCs - unless there are prompt and major changes in the desired numbers, a possibility that largely depends on underlying major changes in the economy and institutions of the country, a shift at high gear into modernization that is likely to be the exception rather than the rule.

If so, a substantial phase of the long-term decline in death rates in the LDCs would also be a phase of catching up with formerly unavailable potentials of desired number of surviving children. The length of this catching-up phase, representing lack of incentive for a response of 
birthrates, is a matter for conjecture. It might differ from one group of LDCs to another; and it would certainly differ in its historical chronology, with disparities in the dates when the major mortality declines began among the different groups of LDCs. But if the natural-increase differences in premodern LDCs were as large as they seem from the scattered data on mortality (and some on fertility, particularly for the peasant communities), being at a minimum 10 points per 1,000 , it might take at least two decades for the catching-up phase to be completed; nor should the possibility of a longer period be ruled out. If so, this phase would largely overlap with any lag due to lack of confidence in the persistence and irreversibility of the mortality trends, discussed under (1) above.

3. The perception of a trend like that in the death rates in the LDCs in recent decades may be limited to that of major absolute declineswhich were concentrated in the early childhood ages, at one end, and in the age brackets beyond the early $50 \mathrm{~s}$ at the other. Following the comment made above, we may ask how the population groups who are in a position to affect birthrates, either because they are of childbearing age or because they exercise influence on those who are, perceive the demographic trends. In the LDCs, in the transition period, and outside the limited upper circles of government, this is hardly done by scrutinizing aggregative statistics or observing graphs. But the answer to how families and the blood-related groups to which they may belong attain their perception of major demographic trends would have to come from greater familiarity with the LDC societies and their mechanisms for ascertaining and diffusing major social data than is possessed here.

One part of the answer is that reduction in the mortality of children, sizable only in the very early ages (below 5 ), is surely observed by those families in procreative phases of their life cycle that enjoy the benefits of such decreased mortality. And it may be legitimately argued that the knowledge of, and reaction to, this part of the downtrend in mortality could be expected to be more direct and potentially effective (other conditions being favorable) than the knowledge of, and reaction to, the decline in mortality at the advanced adult ages. It also follows that if the knowledge of trends is extrapolated into the future, in the process of formulating birth decisions, the reduction in early childhood mortality would be far more likely to form the basis for such an extrapolation than the changes at the advanced adult ages-which would relate to the role of children four or five decades after their birth. To be sure, neglecting these latter, as we do in the statistical illustration that follows, means neglecting the insurance motive of assuring survival of children to ages when they could support their aged parents. But, granted this limitation, it is of interest to explore what an instantaneous and complete response 
to declines in early child mortality would mean for the movements of the rates of natural increase.

The estimates of what we may designate the offset response of birthrates to declines in death rates, presented in table 8.5 , are based on two assumptions: that the response is to reduction in death rates at ages under 5; that the response is prompt and full, allowing for no lag in the process. Both assumptions are unrealistic, the second far more so than the first. But the result is an extreme version of a full major response of birthrates; and it is of interest, in deriving it, to compare it with the actual movement of the birthrates and the trend in the rates of natural increase.

Given these assumptions, we need measures not only of the decline in crude death rates for total population, but also of the decline in the death rates of the population $0-4$. Panel $\mathrm{A}$ of table 8.5 summarizes the results of utilizing the rich data in the United Nations Working Paper repeatedly used here, which shows for individual countries and for regions not only crude birthrates and death rates and total population at quinquennial intervals beginning with 1950 , but also the proportions, in total population, of the $0-4$ group (as well as of other age groups-5-14, etc.). On the reasonable premise that all these demographic parameters are consistent with each other, it is possible to derive, by comparing the cumulated crude birthrates over the quinquennium (related to total population at midpoint of the period) with the surviving 0-4 population at the end of the quinquennium (related to the population at the end of the quinquennium) the proportional attrition (per $1,000)$. If the population is closed, with no emigration or immigration, this attrition rate is identical with the crude death rate for the $0-4$ group. Given the size of the regions we deal with, and the demonstrated closeness between the growth rates in total population and the rates of natural increase, it seemed justifiable to identify the attrition rates thus calculated with death rates relating to the $0-4$ population. The estimates are clearly approximate, but the resulting orders of magnitude are plausible. ${ }^{14}$

With the results in panel $A$, which show the declines in death rates of 0-4 population between 1950-55 and 1970-75 and the proportions of that population in the total at the start of each quinquennium, we can estimate the offset response of birthrates-- on the assumption that birthrates would decline, without any lag, to offset fully the experienced reduction in childhood deaths (panel $B$ ). It will be noted that the derived response was only somewhat larger than the actual decline in birthrates in three of the four LDC regions-a rough agreement that, however, cannot be interpreted to mean that the observed drop in the birthrates did represent the assumed offset response. It could well have 


\begin{tabular}{llllll}
\hline East and & & & & \\
Middle & & Sub- & & \\
South & Middle & Saharan & Latin All \\
Asia & East & Africa & America & Four \\
& $(1)$ & $(2)$ & $(3)$ & $(4)$ & (5) \\
\hline
\end{tabular}

A. The Relevant Demographic Parameters (per 1,000 of underlying population)

Data for 1950-55

1. Proportion of $0-4$ to total population, 1950

2. Proportion of $0-4$ to total population, 1955

3. CRNI, 1950-55

4. 0-4 population in 1955 as proportion of total in 1950 (per 1,000)

5. CBR, 1950-55

6. CBR in line 5, shifted to the base of 1950

$\begin{array}{ccccc}153 & 164 & 170 & 169 & 160 \\ 162 & 169 & 180 & 178 & 168 \\ 18.9 & 24.7 & 20.1 & 28.5 & 21.1 \\ & & & & \\ 178.3 & 190.9 & 198.8 & 204.9 & 186.5 \\ 44.1 & 47.1 & 48.7 & 43.7 & 45.0 \\ 46.26 & 50.06 & 51.18 & 46.88 & 47.41 \\ 247.8 & 276.6 & 283.5 & 257.5 & 260.5 \\ & & & & \\ 63.0 & 71.4 & 68.0 & 42.5 & 64.1 \\ 25.2 & 22.4 & 28.6 & 15.2 & 23.9\end{array}$

7. Cumulative births, 1950-55, as proportion of 1950 population

8. Attrition (death rate) per 1,000 of $0-4$ population in 1950-55, per year (from lines 4 and 7 )

9. CDR, total population, 1950-55

Data for 1970-75

10. Proportion of $0-4$ to total population, 1970

11. Proportion of $0-4$ to total population, 1975

169

173

178

171

171

$\begin{array}{lllll}167 & 171 & 181 & 167 & 170\end{array}$

12. CRNI, 1970-75

$25.4 \quad 28.3$

25.8

29.7

26.4

13. $0-4$ population in 1975 as proportion of total in 1970

$\begin{array}{lllll}190.3 & 196.8 & 205.6 & 193.3 & 193.7\end{array}$

14. CBR, 1970-75

$41.9 \quad 43.1$

$47.6 \quad 38.9$

42.4

15. CBR, to the base of 1970 population

44.51

46.19

50.73

41.85

45.25

16. Cumulative births, $1970-75$, as proportion of 1970 population

240.8

252.9

280.7

230.0

247.7

17. Attrition (death rate) of population 0-4, in 1970-75

$45.4 \quad 48.1$

$59.8 \quad 33.3$

47.4

18. CDR, 1970-75

16.5

14.8

21.8

9.2

16.0 
Table 8.5 (continued)

$\begin{array}{lllll}\begin{array}{l}\text { East and } \\ \text { Middle }\end{array} & & \text { Sub- } & & \\ \text { South } & \text { Middle } & \text { Saharan } & \text { Latin } & \text { All } \\ \text { Asia } & \text { East } & \text { Africa } & \text { America } & \text { Four } \\ (1) & (2) & (3) & \text { (4) } & \text { (5) }\end{array}$

B. Derivation of Offset Response in Birthrates to Decline in Death

Rates of 0-4 Population (all entries per 1,000 of relevant population)

19. Decline in death rates

of $0-4$ population from

$1950-55$ to $1970-75$

23.3

8.2

9.2

16.7

20. Proportion of $0-4$ population to total at initial date

$\begin{array}{lllll}0.17 & 0.17 & 0.18 & 0.18 & 0.17\end{array}$

21. Decline in death rates of $0-4$ population related to total population (line $19 \times$ line 20) $=$ full offset response

22. Observed decline in $\mathrm{CBR}$

$\begin{array}{rrrrr}3.0 & 4.0 & 1.5 & 1.7 & 2.8 \\ 2.2 & 4.0 & 1.1 & 4.8 & 2.6 \\ +6.5 & +3.6 & +5.7 & +1.2 & +5.3 \\ +5.7 & +3.6 & +5.3 & +4.3 & +5.1\end{array}$

23. Observed change in CRNI

24. Derived change in CRNI with full offset response

Notes

All the underlying data are from the United Nations working paper cited and used in connection with table 8.4.

Panel $A$, lines 4 and 13 -The estimates are the proportions in lines 2 and 11 , raised by the cumulative growth of population (cumulative natural increase) over the quinquennium, using the entries in lines 3 and 12 respectively.

Panel A, lines 6 and 15-The estimates use the rise of the base (total) population, but over half rather than the full quinquennium (as it was used for lines 4 and 13 ).

Panel $A$, lines 8 and 17 -The entries in lines 4 and 7 , and 13 and 16 respectively, were used first to derive attrition (deaths) as the difference between lines 7 and 4 , and 13 and 6, related to the initial base (1950 and 1970 respectively) and representing the proportion over the quinquennium. Then the proportion was adjusted for a shift from the 1950 or 1970 base to the $1950-55$ and $1970-75$, using the entries for $0-4$ population in lines 1 and 4 , and 10 and 13 respectively. The adjusted proportions, now to the base of $1950-55$ and $1970-75$ respectively, were then converted into death rates per year.

Panel B-for the rationale, see discussion in the text. Line 19 is the difference between lines 8 and 17 of panel A. Line 20 is based on the shares as shown in lines 1 and 4 , and 10 and 13 , of panel A. Line 22 was derived from the observed CBRs in lines 3 and 14 of panel A. Line 23 was derived from the observed CRNIs in lines 3 and 12 of panel $\mathrm{A}$. Line 24 equals line 23 reduced by the excess of line 21 over line 22 (or raised by the shortage of line 21 relative to line 22 ).

been due to a substantial decline in birthrates of the top economic and social groups, only partly offset by the constancy or slight rise in birthrates among the lower economic groups. In Latin America, the observed decline in birthrates, almost 5 points, greatly exceeded the derived off- 
set of 1.7 points; and this finding is plausible, considering the much longer period over which declines in mortality occurred in Latin America and the greater movement toward the demographic transition that began to affect the birthrates.

But the major aspect of the finding in panel B is that even if we assume full and instantaneous response to declines in child mortality, such a response will not be sufficient to prevent a major rise in the rate of natural increase. As line 24 shows, the derived rate of natural increase shows a substantial rise over the two-decade span in all of the four LDC regions.

The results are as one would expect. If the birthrates respond to declines in child mortality alone, the rates of natural increase will be raised by the declines in mortality in ages above those of childhoodand largely by reduced mortality in the advanced adult ages. If we were to allow for effects of deaths also of children 5 years of age and over, there would be a somewhat larger, but not much larger, offset response. If, as partial data indicate, total deaths of children under 15 were only about $60 \%$ of total deaths, while the share of the $0-14$ group ranged about $42 \%$ of total population, the implicitly more moderate level and decline of death rates for ages 5-14 than for the 0-4 populations might, if taken into account, raise the estimated offset decline in line 21 by about a tenth, but not more than that.

The major conclusion is that if it is largely childhood deaths that affect the birthrate response, then even a full and prompt response (neither likely) would be insufficient to prevent a substantial rise in the rates of natural increase. Under the assumed conditions, the latter will cease rising only when the death rates above the childhood ages cease declining. Or, to put the conclusion in its converse form, while death rates are declining-sharply and with the usual concentration in early and advanced ages-the possibility of avoiding large rises in the rates of natural increase would lie not so much in a response of birthrates to child mortality (a most likely response, yet even so not promptly or fully) as in changing conditions that would affect the total number of surviving children desired. Such changes in conditions are not automatically provided by declines in death rates and by those factors behind them that appeared to operate in the LDCs in recent decades. On the contrary, the conjectures under (2) suggest a long initial period in the decline of death rates when the desired number of surviving children may continue to remain above that yielded by declining child mortality levels.

But what are the implications of our discussion of the responses of birthrates to the declines in death rates? At the end of the preceding subsection, which dealt with the declines in death rates, we came to a 
rather uncertain conclusion on the effects of the greater declines in death rates among the lower economic and social groups than among the upper groups, for whom death rates were already appreciably lower because of better nutrition, housing, and so on. We argued that prolongation of life, and closer convergence of death rates among various economic and social groups, removed one major aspect of long-term inequality. This reduction could be offset by greater pressure of higher rates of population growth on scarce traditional resources, unless such pressure was relieved by economic and social innovations associated with modern economic growth. We now add the conclusion that even with full and prompt offset response of birthrates to declines in death rates of 0-4 population, there will be acceleration of rates of natural increase; and such acceleration will be greater among those groups for whom the declines in death rates were greater, that is, among the lower economic and social strata. And this should mean that instead of a positive association between economic and social levels and group rates of natural increase, the trends discussed will produce an inverse association between economic and social levels and rates of natural increase. But this does not imply a necessary widening of per capita income inequalities if we deal with long-term levels of life-cycle income-which will be sustained by the longer span over which life and productivity can now be maintained among the lower income groups, as they could not be so maintained in the pretransition past. The conclusion is still uncertain; but one may argue that both the trends in the birthrates and the trends in income inequality depend heavily on economic and social transformations that relieve the pressure of growing population on the scarcity of traditional resources and that induce downtrends in the birthrates beyond those derivable as offset responses to declines in child mortality.

This latter argument could be developed further by indicating that the technological innovations associated with modern economic growth, which are the main source of the economic advance, depend heavily upon new knowledge; and that they and the associated social innovations require a much greater emphasis on higher levels of education and training of the younger generation that would be carrying the innovational process further. Once this connection between investment in the younger generation and further economic and social advance is established, there will be a shift toward greater investment by the older generation in the young (away from the earlier pattern of the younger generation contributing to their elders within the wider family), ${ }^{15}$ with a resulting change in the number of desired surviving children, having major effects on birthrates. The important link in this argument is between the sources of economic advance and the contribution needed from the younger generation if these sources are to be maintained-a contribution that demands greater investment in education and training. 
And it is in this connection that a decline in death rates of the type that has occurred in LDCs in recent decades looms as an indispensable condition. How the eventual declines in birthrates develop, whether they begin at the top, and how rapidly they spread through the wider groups in the population are questions and possibilities with obvious bearing upon income distribution while the transition process is taking place. But these arguments take us well beyond the immediate effects of the death rate trends in the LDCs, the major movement so far observed. And it would require more analysis of the differential death rate movements and of the related movements in birthrates to permit adequate discussion of the wider interconnections just suggested.

\section{Appendix. Economic Losses Represented by Deaths: Exploratory Illustrations}

In this appendix we discuss economic losses represented by deaths, with special attention to the differences between the high death rates of the LDCs and the much lower mortality of the MDCs. The discussion is directly relevant to the effects of the major declines of the death rates in the LDCs emphasized in the text. But, in view of the complexity and the difficulty of arriving at defensible approximations even of the order of magnitudes, it seemed best to shift the exploration to a separate appendix.

The discussion is limited to direct economic costs or losses. No attempt is, or can be, made to attach magnitudes to the psychological and emotional effects of death upon members of the family. Nor can we deal with indirect negative effects-for example, the greater unpredictability and variability over time of mortality in conditions of limited control over disease.

An even more important exclusion is the neglect of the association between high death rates and high levels of morbidity-that is, incidence of disease apart from higher mortality. Given this association, the level of death rates clearly suggests the level of morbidity; and higher incidence of disease either in childhood or in adulthood would presumably have negative effects on productivity, either because of the lasting debilitating effects of an earlier disease (even if incurred in childhood) or because of direct consequences of such diseases affecting adults of working age. Any attempt to measure the losses so involved in LDCs, in comparison with those in the MDCs, would run into the difficulty of separating the effects of health conditions from those of nutrition and other components of the standard of living. But it is reasonable to as- 
sume that these losses from higher morbidity associated with higher death rates in the LDCs are significantly greater than similar relative losses in the MDCs. If so, the comparison of economic losses suggested by deaths in the discussion that follows underestimates the excess relative loss in the less developed countries.

In dealing here with direct economic losses debited to deaths, we use for illustration the relevant demographic data for 1937 for two countries, Egypt and the Netherlands (see table 8.A.1, panel A). With

Table 8.A.1 Economic Losses Implicit in Death Rates: An Illustrative Calculation, Egypt and the Netherlands, 1937

\begin{tabular}{|c|c|c|c|c|c|c|}
\hline \multirow[b]{3}{*}{ Age Class } & \multicolumn{6}{|c|}{$\begin{array}{l}\text { A. Distributions of Population and Deaths by } \\
\text { Age Classes, and the Age-Specific Death Rates }\end{array}$} \\
\hline & \multicolumn{3}{|c|}{ Egypt } & \multicolumn{3}{|c|}{ The Netherlands } \\
\hline & $\begin{array}{l}\% \text { Share } \\
\text { Population } \\
\text { by Age } \\
\text { (1) }\end{array}$ & $\begin{array}{l}\text { \% Share } \\
\text { Deaths } \\
\text { by Age } \\
\text { (2) }\end{array}$ & $\begin{array}{l}\text { ASDR } \\
\text { per } \\
1,000 \\
(3)\end{array}$ & $\begin{array}{l}\text { \% Share } \\
\text { Population } \\
\text { by Age } \\
\text { (4) }\end{array}$ & $\begin{array}{l}\% \text { Share } \\
\text { Deaths } \\
\text { by Age } \\
(5)\end{array}$ & $\begin{array}{l}\text { ASDR } \\
\text { per } \\
1,000 \\
(6)\end{array}$ \\
\hline 1. Below 1 & 3.1 & 26.5 & 234.4 & 2.2 & 8.6 & 34.3 \\
\hline 2. $1-4$ & 10.2 & 29.5 & 78.9 & 8.1 & 2.6 & 2.8 \\
\hline 3. $5-9$ & 14.0 & 3.9 & 7.6 & 9.8 & 1.2 & 1.1 \\
\hline 4. $10-14$ & 12.1 & 2.0 & 4.5 & 9.2 & 0.9 & 0.9 \\
\hline 5. $0-14$ & 39.4 & 61.9 & & 29.3 & 13.3 & \\
\hline 6. $15-24$ & 15.4 & 3.2 & 5.6 & 17.8 & 3.1 & 1.5 \\
\hline 7. $25-34$ & 15.7 & 4.4 & 7.7 & 15.4 & 3.6 & 2.1 \\
\hline 8. $35-44$ & 13.1 & 4.9 & 10.1 & 13.0 & 4.8 & 3.2 \\
\hline 9. $45-54$ & 8.3 & 4.5 & 14.7 & 10.3 & 7.7 & 6.6 \\
\hline 10. $55-64$ & 4.5 & 4.1 & 24.8 & 7.5 & 14.4 & 16.9 \\
\hline 11. $15-64$ & 57.0 & 21.1 & & 64.0 & 33.6 & \\
\hline 12. 65 and over & 3.6 & 17.0 & 127.2 & 6.7 & 53.1 & 69.6 \\
\hline 13. Total & 100.0 & 100.0 & 27.27 & 100.0 & 100.0 & 8.78 \\
\hline \multicolumn{7}{|c|}{ B-1. Economic Losses from Child Mortality } \\
\hline & \multicolumn{3}{|c|}{ Egypt } & \multicolumn{3}{|c|}{ The Netherlands } \\
\hline Age Class & $\begin{array}{l}\text { Deaths, \% } \\
\text { of Total } \\
\text { Population } \\
\text { (1) }\end{array}$ & $\begin{array}{l}\text { Loss } \\
\text { Multiple } \\
(2)\end{array}$ & $\begin{array}{l}\text { Loss, \% } \\
\text { of } 100 \\
\mathrm{CU} \\
(3)\end{array}$ & $\begin{array}{l}\text { Deaths, \% } \\
\text { of Total } \\
\text { Population } \\
\text { (4) }\end{array}$ & $\begin{array}{l}\text { Loss } \\
\text { Mul- } \\
\text { tiple } \\
(5)\end{array}$ & $\begin{array}{l}\text { Loss, \% } \\
\text { of } 100 \\
\text { CU } \\
(6)\end{array}$ \\
\hline 14. Below 1 & 0.7266 & 0.25 & 0.1817 & 0.0755 & 0.25 & 0.0189 \\
\hline 15. $1-4$ & 0.8048 & 1.50 & 1.2072 & 0.0227 & 1.50 & 0.0340 \\
\hline 16. $5-9$ & 0.1064 & 3.75 & 0.3990 & 0.0108 & 3.75 & 0.0405 \\
\hline 17. $10-14$ & 0.0545 & 6.25 & 0.3406 & 0.0083 & 6.25 & 0.0519 \\
\hline 18. $0-14$ & 1.6923 & & $\begin{array}{r}2.1205 \\
(2.681)\end{array}$ & 0.1173 & & $\begin{array}{r}0.1453 \\
(0.174)\end{array}$ \\
\hline
\end{tabular}


B-2. Residual Economic Losses, Adult Mortality

\begin{tabular}{|c|c|c|c|c|c|c|c|c|}
\hline \multirow[b]{2}{*}{$\begin{array}{l}\text { Class } \\
\text { Age }\end{array}$} & \multicolumn{3}{|c|}{ Egypt } & \multicolumn{5}{|c|}{ The Netherlands } \\
\hline & $\begin{array}{l}\text { Deaths, } \\
\% \text { of } \\
\text { Total } \\
\text { Popula- } \\
\text { tion } \\
\text { (1) }\end{array}$ & $\begin{array}{l}\text { Assumed } \\
\text { Output } \\
\text { per } \\
\text { Person } \\
\text { (CU) } \\
\text { (2) }\end{array}$ & $\begin{array}{l}\text { Residual Cost } \\
\text { Beginning } \\
\text { of Age } \\
\text { Class } \\
\text { CU's } \\
(3)\end{array}$ & $\begin{array}{l}\text { Resid- } \\
\text { ual } \\
\text { Loss, } \\
\% \text { of } \\
100 \mathrm{CU} \\
(4)\end{array}$ & $\begin{array}{l}\text { Deaths } \\
\text { (5) }\end{array}$ & $\begin{array}{l}\text { Output } \\
(6)\end{array}$ & $\begin{array}{l}\text { Resid- } \\
\text { ual } \\
\text { Cost } \\
(7)\end{array}$ & $\begin{array}{l}\text { - Resid- } \\
\text { ual } \\
\text { Loss } \\
(8)\end{array}$ \\
\hline 19. $15-24$ & 0.0862 & 1.000 & 7.50 & 0.6465 & 0.0267 & 1.000 & 7.50 & 0.2002 \\
\hline 20. $25-34$ & 0.1209 & 1.322 & 7.50 & 0.7121 & 0.0327 & 1.224 & 7.50 & 0.2061 \\
\hline 21. $35-44$ & 0.1323 & 1.644 & 4.28 & 0.1402 & 0.0416 & 1.449 & 5.26 & 0.1256 \\
\hline 22. $45-54$ & & 1.644 & -2.16 & & & 1.449 & 0.77 & \\
\hline 23. Total & & & & $\begin{array}{r}1.4988 \\
(1.888)\end{array}$ & & & & $\begin{array}{r}0.5319 \\
(0.636)\end{array}$ \\
\hline $\begin{array}{l}\text { 24. Total, } \\
\text { B-2, }\end{array}$ & $\begin{array}{l}\text { for panel } \\
6 \text { of total }\end{array}$ & $\begin{array}{l}\text { ls } \mathbf{B}-1 \text { and } \\
\text { product }\end{array}$ & & 4.57 & & & & 0.81 \\
\hline
\end{tabular}

Notes

Panel $A$-The data used here are taken, or calculated, from United Nations, Demographic Yearbooks, 1949-1950, and 1951 (New York, 1950, 1951). The distribution of the population by age for Egypt is for late March 1937, and is from the 1949-50 Yearbook, table 4, pp. $104 \mathrm{ff}$; that for the Netherlands is the average of the percentage shares for 1930 and 1945 , from the same table. The small fraction of age-unknown is allocated proportionately. The distribution of deaths by age is from United Nations, Demographic Yearbook, 1951 (New York 1951), table 16, pp. $216 \mathrm{ff}$., and relates to the deaths in 1937 for both countries.

The age-specific death rates in column 3 are derived by relating the absolute numbers of deaths to the relevant population; but the multiplication of the ratio of column 2 to column 1 by the crude death rate (line 13 , col. 3 ) yields identical results, except for errors of rounding. The age-specific death rates in col. 6 were derived by multiplying the ratio of col. 5 to col. 4 , by the crude death rate in line 13 , col. $6(8.78)$.

Panel $B-1$, cols. $I$ and 4 -The entries were derived by multiplying the age-specific death rates (see panel A, cols. 3 and 6), expressed as proper fractions, by the percentage share of the age-class in total population (see panel A, cols. 1 and 4).

Panel B-1, cols. 2 and 5-Entries were calculated on three assumptions: (a) Consumption per child is 0.5 of that for the adult in working ages (15-64). (b) Total income of the country is the sum of all consumption units, the latter being 0.5 per child; 1.00 per adult in working ages; 0.75 per adult aged 65 and over. (c) The number of years within the life-span of the children dying is $0.5,3.0,7.5$, and 12.5 respectively for each successive age class under 15-representing linear interpolation and cumulation of the age-class limits. The entries in cols. 2 and 5 are then the products of 0.5 by the number of years.

Panel B-1, cols. 3 and 6 -The entries are the products of those in cols. 1-2, and 4-5-for lines 14-17; and direct sums in line 18. The entries in parentheses in line 8 , cols. 3 and 6 , are the total loss related to the total number of consuming units. Based on the assumptions stated above, the latter total for Egypt is: (39.4\%) $(0.5)+(57.0 \%)(1.0)+(3.6 \%)(0.75)=79.4$; and for the Netherlands, using a similar equation-83.675. Division by these totals used as proper fractions (to 100) yields the percentages in the parentheses.

Panel B-2, cols. 1 and 5-These again are the products of the age-specific death 
further search, we probably could have found the data for a wider contrast with respect to death rates, both crude and age-specific. But the contrast observed in panel $\mathrm{A}$ in the crude death rates, between 27.3 per 1,000 for Egypt and fewer than 9 per 1,000 for the Netherlands, is wide enough for our purposes. The intention is to suggest the wider ramifications of the comparison with respect to the economic losses involved-rather than attempt a full estimate of the orders of magnitude.

A glance at the age-specific death rates in columns 3 and 6 of panel A reveals that these rates are higher in Egypt than in the Netherlands for each age class distinguished; that the ratios of the age-specific death rates in Egypt to those in the Netherlands tend to be higher in the early ages than at later ages, the decline in these ratios being interrupted only by the extremely high ratio for the 1-4 age class; and that the greater share of the younger age groups--particularly those below 15-in the total population, in Egypt than in the Netherlands, tends to accentuate the disparity in the crude death rates. Whatever losses are represented by deaths are bound to be much greater in a high death rate country like Egypt, at least in relation to its total economic magnitude, than in a low death rate country like the Netherlands. It also follows that if the

rates by the proportion of the age class in total population, both being taken from panel $A$ (see notes to panel $A$ ).

Panel B-2, cols. 2 and 6-The life-cycle pattern of product per capita in the working ages (and also for age 65 and over) is based on the following assumptions: (a) The product per capita in age 65 and over is $0.75 \mathrm{CU}$, just sufficient to cover consumption. It follows that the product per capita for ages 15-64 must cover more than the per capita $\mathrm{CU}$, to compensate for the consumption of children under 15. The average excess in per capita product in ages 15-64 is given by the ratio of all consumption units for people under 65 to the number of people of working age (i.e., for Egypt $[(39.4 \times 0.5)+(57.0 \times 1.0)]$ divided by 57.0 ; for the Netherlands $[(29.3 \times 0.5)+(64.0 \times 1.0)]$ divided by 64.0 . (b) It is assumed that in the age class $15-24$ product per capita just equals consumption, i.e., 1.0; that there is a peaking plateau in ages $35-44$ and $45-54$, per capita product being equally high in the two age classes; and that in the intermediate age classes (25-34 and $55-64)$, the per capita product is a simple average of the preceding and following class means. Given assumptions $(a)$ and $(b)$, it is possible to solve a one-variable equation to find the value of the peak level (which proves to be 1.644 in Egypt and 1.449 in the Netherlands), and thus of all the lower-class product per capita.

Panel B-2, cols. 3 and 7-The initial value here is the product of $0.5 \mathrm{CU}$ (consumption per person per year) by 15 , the number of years elapsing to the beginning of the 15-24 age class. From then on the cumulated past costs are affected by the surplus of product over assumed consumption in the successive age classes of adults of working age - the surplus being the difference between the entries in cols. 2 and 6 , and 1.00 .

Panel B-2, cols. 4 and 8-The entries are product of the entries in cols. 1 and 4, by the average of those in cols. 3 and 7 (e.g., for line 20 , it would be the average of 7.50 and 4.28 , in col. 4 ; and of 7.50 and 5.26 in col. 8)-all of this for lines 19 through 22 .

For entries in lines 23 and 24 , whether the sums are in top lines or in the parentheses, see notes to the relevant part of panel B-1. 
recent major declines in the LDCs proceeded on the path suggested in the text, with larger declines among the lower economic and social groups with initially much higher mortality than among the more favored, upper economic groups, the resulting convergence within the country among group death rates would also mean convergence in the relative burden of losses represented by deaths. But how do we estimate, as a first approximation, the direct economic losses that deaths represent?

Two approaches may be followed. In the first, the losses represented by deaths would be defined as inputs into past consumption of children and young adults offset by productive contributions that the deceased might have made. The question being answered, then, is What unoffset consumption inputs might have been avoided if the children and young adults whose deaths we are considering had never been born? In the other approach, the losses represented by deaths are viewed as the projected net productive contribution of the deceased that could have been expected but for the irreversible loss. This is the lost opportunities, rather than the lost costs, approach; but both deal only with economic costs, opportunities, and returns, not with the psychic. We follow here the first approach, carried through more easily and dealing with historical facts and incurred burdens, rather than with extrapolated possibilities and lost future opportunities. ${ }^{16}$

Panel B-1, columns 1 and 3, reveals that total childhood deaths in a year account for $1.7 \%$ of total population in Egypt, but only $0.117 \%$ in the Netherlands (line 18) -a ratio of more than 14 to 1 . To estimate the input into these children to whose death we are trying to assign an economic weight, we are assuming that the annual consumption per child amounted to 0.5 of the consumption of an adult of working age; that the productive contribution of children was negligible and that no offset to the input of past costs is thus to be entered; that with stable prices, there was no rise over time in per capita consumption of the adults of working age; and that with savings minimal (and disregarded for simplicity), total income (or net product of the nation) was the sum of all consumption (calculated by assigning 1.0 per adult of working age, 0.50 to those below 15 , and 0.75 to those 65 and over). Given these assumptions, and cumulation of inputs into children who died after year 0 , we can calculate the cost as a pcrcentage of total current product. It works out to $2.68 \%$ for Egypt and $0.17 \%$ for the Netherlands (see line 18 , cols. 3 and 6 , in parentheses).

It is of interest to compare the results in table 8.A.1 with those in Hansen's note (Hansen 1957), which reports measures for India similar to those for the United Kingdom and the United States, for 1931 and 1951 (see table 8.A.2). 
Table 8.A.2

Major Results of Hansen's Calculations of Costs of Childhood Deaths

\begin{tabular}{llll}
\hline & $\begin{array}{l}\text { India } \\
\text { (1) }\end{array}$ & $\begin{array}{l}\text { United Kingdom } \\
(2)\end{array}$ & $\begin{array}{l}\text { United States } \\
(3)\end{array}$ \\
\hline $\begin{array}{l}\text { Deaths before age 15 as } \\
\text { \% of total population }\end{array}$ & & & \\
1. 1931 & 1.58 & 0.17 & 0.18 \\
2. 1951 & 1.31 & 0.07 & 0.08 \\
Costs of childhood deaths, & & & \\
child-adult consumption & & & 0.32 \\
ratio set at 0.5 & & & 0.09 \\
3. 1931 & 2.81 & 0.26 & \\
4. 1951 & 2.83 & 0.07 & 0.40 \\
Costs of childhood deaths, & & & 0.12 \\
child-adult consumption & & & \\
ratio variable & & 0.35 & \\
5. 1931 & 2.78 & 0.09 & \\
6. 1951 & 2.82 & & \\
Notes & & & \\
\hline
\end{tabular}

Notes

Taken or calculated from tables 2 and 3, pp. 259-60, of the paper cited in note 19.

The costs of childhood deaths are cxpressed in percentages of the country's total product, equated to aggregate consumption.

The variable child-adult consumption ratios in lines 5 and 6 were as follows. For India, the ratio was set at 0.5 through age class 5-9, and at 0.8 for age class 10-14. For the United Kingdom and the United States, the ratios for the four successive age classes (the same as used here) were $0.6,0.7,0.8$, and 0.9 .

The comparison with the results here confirms the general orders of magnitude and indicates how differences in the assumed child-adult consumption ratios affect the cost of childhood mortality expressed as a percentage of total product. While we have assumed here the childadult consumption ratio of 0.5 , adults defined as people of working age (and with the consumption level per person of 65 and over set at 0.75 ), the resulting cost estimate for Egypt, at $2.7 \%$, is close to that for India, either in 1931 or 1951 - see lines 3-4, col. 1). And the introduction of a somewhat greater consumption allowance for the age group 10-14 in India does not change the cost estimate significantly (see lines 5-6, col. 1). In contrast, introducing higher child-adult consumption ratios for the United Kingdom and the United States raises the cost estimates by a substantial proportion (from 0.26 to 0.35 in United Kingdom in 1931, and from 0.32 to 0.40 for the United States in the same year; the proportional changes in 1951 are almost as great, see columns 2 and 3, lines 3-6). Yet, even with the allowance for much higher consump- 
tion levels (relative to adults) of children in the United Kingdom and the United States, the relative costs of childhood deaths for India are still much greater in 1931 and 1951.

But if deaths of children represent an economic loss because of past input of resources that cannot be recovered, the same is true of the deaths of adults of working age-so long as the surplus of their contribution to product beyond their own consumption fails to cover past historical costs incurred in raising them to productive ages. This is the rationale for panel B-2 of table 8.A.1, in which the cumulative input in past consumption (at 0.5 units until age 15, and at 1.0 through the successive ages until age 65) is compared with the cumulative total output credited to the adults. The latter output is estimated on two assumptions: $(a)$ that it is the adult population of working age, 15-64, who produce the goods sufficient for their consumption and that of children under $15 ;(b)$ that within the working life-span, output per person age 15-24 just equals per capita consumption (i.e., 1.0); that the peak per capita output is a plateau at ages $35-44$ and $45-54$; and that per capita product in the intermediate age classes $(25-34$ and $55-64)$ is at an arithmetic mean of the per capita products in the preceding and folling age classes. This is clearly only a rough approximation to the life cycle of product per adult; but some such pattern is needed for a proper view of the time span within which the accumulated excess of output over consumption begins to match the accumulated past input into consumption-for the proportion of population that dies and for whom full recovery of past costs cannot be attained.

The results of the estimates in panel B-2 (for details of the procedure see the notes to the table) suggest that for Egypt the costs of mortality in the adult ages when past costs are recovered adds an item equivalent to $2 \%$ of product, raising the total past costs of child and early adult mortality to $4.6 \%$ (see lines $23-24$, col. 4). For the Netherlands, the addition, while smaller absolutely $(0.64 \%)$, is far greater relative to cost of child mortality. This is due to the much greater weight of costs in col. 7, lines 19-22, than in col. 5, lines 14-17; whereas total mortality (as percentage of total population) in ages $15-44$, of 0.1010 (see col. 5, lines 19-21) is not much lower than the corresponding total of 0.1173 for ages $0-14$ (see line 18 , col. 4 ).

Only further exploration, involving many more countries, would reveal whether the approximation to unrequited past costs represented by child and early adult mortality (introduced by the estimates in panel B-2) is typical of less developed and developed countries respectively. But there is one aspect of the estimates underlying panel B-2 that is likely to be typical and deserves explicit note. If the adult population of working age is assumed to produce sufficiently to cover both its own 
consumption and that of the population ages $0-14$, the average per capita output for the adult working-age population of Egypt would have to be $76.7 / 57.0=1.346$; whereas that for the Netherlands would have to be $78.65 / 64.0=1.229$. In other words, the excess output demanded from adults of working age in Egypt is proportionately greater than that demanded from the adults of working age in the Netherlands. This reflects a dependency ratio that, whether or not we exclude dependency in ages of 65 and over (it was excluded by our assumption), is significantly greater in LDCs than in MDCs. The source lies in the higher ratio of children to adults of working age-which, for Egypt, amounted to $39.4 / 57.0=0.69$; whereas in the Netherlands it was $29.3 / 64.0=0.46$. It is the difference in these two ratios, combined with assumptions concerning the life-cycle pattern of product per capita within the working ages, that results in a contrast, at the peak plateau, between an output index of 1.664 for Egypt and one of 1.449 for the Netherlands. The implicit question is whether, given average levels of productivity, it is possible to muster such a high excess ratio, or whether, in order to achieve the latter, the whole average level of output in the productive ages would have to be lowered. If both the child-adult consumption ratios and the proportions of children to working-age adults are fixed, the adjustment may be either in the average level of the product or in the pattern; and if the pattern is fixed, the adjustment is limited to the average level-implicitly involving the lowering of consumption for both children and adults.

Assuming for purposes of argument that the results in both panel B-1 and panel B-2 can be viewed as typical, what importance can be assigned to the indicated differences in the economic costs of child and early adult mortality between a less developed and a more developed country? The answer can be suggested only after we take a brief account of the major omissions in the calculations, even allowing (as Hansen did) for a higher child-adult consumption ratio in a developed than in a less developed country.

The first major omission is neglect of the contribution of the mother's engagement in pregnancy, birth, and the immediate burdens of care in infancy - the cost estimates here relating only to the consumption of goods and services by children. The weight of such omission would vary even among less developed countries, depending on institutional practices and the role of women in productive activity; and it is not clear that differences in the weight of this particular cost component can be surmised in comparisons between less developed and developed countries (such costs always viewed as proportions of some overall economic product magnitude). It clearly adds to the absolute costs of child mortality in both groups of countries and thus adds to the accumulated costs 
that would have to be debited against the output in the early working ages (in estimating the costs of deaths at those age levels); but we have no basis here for any plausible comparisons.

The second omission is of a possible allowance for effects of growth in per capita product on the estimate of past costs embodied in economic loss from childhood (or young adult) mortality. If such growth does occur, the current burden is lessened, since past consumption of children and younger adults is lower in proportion to current per capita consumption, and hence in relation to current product. Here the difference in this respect between LDCs, with their much lower growth rates in per capita product (or even absence of growth in many cases in premodern periods), and the MDCs, with their higher and steadier rates of growth in per capita product, is clearly in favor of the latter-reducing more appreciably the ratio of past costs to current output. The magnitudes, and their differences as between LDCs and MDCs, could be calculated using assumptions now used in table 8.A.1 and introducing illustrative rates of past growth in per capita product.

The third omission, of potentially large magnitude, is that of foregone yields on past costs. These yields are possible even if we retain the oversimplified assumption that equates total product with total consumption and thus completely neglects savings and capital. Even under such conditions, were it have been possible to dispense with past consumption of children or young adults whose deaths we are evaluating, the consumption of surviving adults would have been greater-with effects on productivity, which would be likely to have been greater in LDCs than in MDCs. This greater consumption foregone would also have meant greater productivity in the past-a loss that presumably would be, in terms of current product, proportionately greater in LDCs than in MDCs. An alternative way to evaluate this omission is to allow for interest yield on past costs, and for the presence of capital returns in the economy. If, for the sake of an illustration, we allow for an addition of returns on capital equal to a quarter of total consumption, and use a $5 \%$ return rate on past consumption in children viewed as an investment, the application of these rates to panel B-1, columns 2-3 and 5-6, lines 14-17 would yield an estimate of accumulated losses (to age 15) of 3.5014 in column 3 for Egypt and of 0.2165 in column 6 for the Netherlands, which - with rough allowance for the rise in the total product denominators by $25 \%$-would work out to percentages of 3.528 and 0.207 respectively, a wider contrast than between the entries in parentheses in line 8 , columns 3 and 6 . This would also affect estimates of losses in the younger adult age classes in panel B-2.

Finally, there is a question similar to that discussed in the text in connection with the focus of decision in the response of birthrates to the declines in death rates. Here the question is who bears the costs 
of childhood mortality or the residual losses involved in the death of adults in the younger working ages. The question may not be relevant for the economy as a whole. But if we are concerned with differential effects of these losses on different economic and social groups within the population, the question of who bears them becomes relevant. Thus in many developed countries the state, in various ways, assumes part of the costs of children and young adults-that is, part of their consumption - even though it may finance the activity from taxes on the income of adults and families, with the burden perhaps falling more heavily on the higher-income families. In many less developed countries, there may also be sharing of such costs within the larger blood group, rather than the full cost falling on the individual family unit. These comments suggest that the question of how the economic losses of mortality have been shared involves complicated effects of benefits and incidence of taxes in those developed societies where the state assumes increasing responsibility; of separation or jointness between the parental family and that of the next generation (bearing particularly on the locus of mortality costs for the younger age classes within the working life-span); and of the relation between the single family, no matter how widely defined, and the wider blood-related group of which it may be a member.

It is not feasible here to explore the variety of omissions just indicated and to probe the interrelated and intricate questions they suggest. The discussion of differential costs of mortality, like that of the offset response of birthrates to declines in death rates, emphasizes that the analysis must take account of the wide variety of institutional, economic, and social groupings that condition the impact of losses involved in deaths at different ages or that shape the response of birthrates to declines in mortality. With inadequate data to indicate the differences in the framework among various groups of LDCs and MDCs, and with limited command over the monographic literature, the probing had to be limited and constrained by oversimplifying assumptions.

Despite these limitations, the discussion above is, I believe, sufficient to suggest the minimum relative magnitudes of the losses represented by deaths of children and younger adults-and the large differences in these losses between MDCs and LDCs on the eve of the recent major downtrends of the death rates in LDCs. The proportionate losses represented by the death rates in the LDCs relating to children and younger adults approximate at least $5 \%$ of the current product, compared with probably less than a fifth of that proportion in the developed countries; and reasonable adjustments of these shares, to take account of the omissions, could easily raise these minimal ratios to twice their indicated levels.

Comparisons of LDCs and MDCs are only suggestive of comparisons within a less developed country between the mortality experience of the lower economic and social groups and that of the higher, more favorably 
situated. Yet given the possibility of substantial differences in mortality within the LDCs, associated before the 1920 s largely with disparities in economic and social status, one can reasonably assume that in those earlier decades the burden of economic losses of mortality were much heavier relative to the consumption and income levels of the lower income groups than they were for the upper economic and social groups; and that the convergence in death rates, and reduction in overall levels associated with the recent technological breakthroughs in control of death and of public health, also meant reduction in the inequality of the burden of relative losses of mortality at these different economic and social levels. And one must repeat, in conclusion, the comment made at the outset - that death rates are significant as indexes of morbidity and that declining and converging morbidity rates may have direct effects on related disparities in productivity among the various economic and social groups within a less developed country as it benefits from declining mortality.

\section{Notes}

1. We prefer to emphasize the total for LDCs, excluding China. The estimates for the latter before the 1950s were always subject to debate; and there has been ever greater scarcity of data for China since the 1950s. Yet the estimated population for the country accounted for 0.2 of world population for 1975, and about 0.3 of the population total for the LDCs.

2. The quinquennium $1970-75$ and the estimate for 1975 are described as a projection even in the more recent United Nations sources; and we used the medium variant. But since estimates for this recent period could not deviate substantially from the actual, at least with respect to change from the preceding two decades, we felt justified in including them to form an observed 25-year span, 1950-75.

3. Kingsley Davis (1951) estimated the death rate for India by decades from 1881-91 to 1931-41, showing a level of about 43 per 1,000 in the first three decades, a bulge in 1911-21 (associated with the influenza pandemic of 1918) to 48.6, and a decline to 36.3 in 1921-31 and to 31.3 in 1931-41 (p. 37). The estimated crude birthrates were set at between 46 and 49 in the first four of the six decades, and then at 46 in 1921-31 and 45 in 1931-41 (p. 69). This combination of relative constancy of the birthrate between 1920 and 1940 , with a substantial decline in the death rate, is what we are assuming in the tentative calculation in the text.

4. See particularly the paper in this volume by Samuel H. Preston (chap. 5), "Causes and Consequences of Mortality Declines in Less Developed Countries during the Twentieth Century," for a wide-ranging summary and bibliography. I also found a wealth of data and interpretation in the articles by George H. Stolnitz, beginning with the two-part paper "A Century of International Mortality Trends" (Stolnitz 1955, 1956), reviewing the evidence to 1950, and concluding 
with the Iatest, "International Mortality Trends: Some Main Facts and Implications" (Stolnitz 1975).

5. A useful brief description of the assumptions underlying the projections, and the criteria of plausibility used in selecting them, is in United Nations (1966, chap. 2, pp. 6-7). A wider review of the field is in United Nations (1973, 1:558-88).

6. It is possible to secure from United Nations, Demographic Yearbook 1957, the distribution of population among continents and subcontinents in 1920, as well as of the land area (including internal waters); and we find in Clark (1957) a distribution of land among major parts of the world, the land evaluated with respect to rainfall, temperature, and other climatic factors that affect suitability for intensive cultivation (table 33, inset before p. 309). Comparing the large areas within the group that comprises the LDCs we find the following percentage distributions (LDCs, comprising the regions distinguished $=100$ ):

$\begin{array}{lccc} & \text { Population } & & \text { Land in } \\ & (1920) & \text { Total Land } & \text { Standard Units } \\ \text { East and Southeast Asia } & 77.0 & 24.8 & 29.4 \\ \text { Southwest Asia } & 3.7 & 8.2 & 1.3 \\ \text { Africa } & 11.7 & 39.4 & 31.8 \\ \text { Latin America } & 7.6 & 27.6 & 37.5\end{array}$

East and Southeast Asia in the first line is dominated by the Sinic and Hindic group; and the capacity shown to sustain enormous populations with a land endowment that is less than a third of that in the rest of the less developed world is striking.

7. In 1920, of some 1,187 million population estimated in the less developed regions (defined as countries outside of Europe, North America, Japan, the Soviet Union, Australia and New Zealand, and temperate South America), only 69 million were living in places with populations of 20,000 or more. While this low percentage-less than $6 \%$-was Iargely due to the dominance of Asia, a level of slightly over $10 \%$ was the highest shown for any subregion. See United Nations (1969, tables 47-49, pp. 115-17).

8. See Davis (1951); the conversion ratio used in the text is described on p. 36 . The data on children born and surviving to rural families in Punjab in 1939 for various occupational class groups are in table $26, \mathrm{p} .78$, with discussion in the text (p. 76) stressing some limitations of the data.

9. The data are from U.S. Bureau of the Census (1975). The series on gross and net reproduction rates are series $B 36-41$, p. 53 ; those on crude birthrates are series B5-10, p. 49; and those on crude death rates are series $B 167-80$, p. 59 .

10. See, e.g., a recent paper by Ajami (1976, pp. 453-63), and the literature cited therein, particularly the early paper by Stys (1957, pp. 136-48).

11. For a brief discussion of the relation between the health revolution and economic development, see the paper by the World Health Organization, "Health Trends and Prospects in Relation to Population and Development," in United Nations (1975). The same paper contains some discussion of the relation between the decline in infant mortality and the birthrate.

12. In this connection one may refer to two papers on population growth and income distribution in the United Nations volume, Population Debale (1975, vol. 1). The first, by Dharam P. Ghai, "Population Growth, Labour Absorption, and Income Distribution" (pp. 502-9), summarizes the conclusions by listing in table 2 (p. 509) the effects of population growth on income distribution-under two major headings of "high fertility" and "reduced fertility"-with the levels and trends 
of mortality not mentioned. In the other paper, by H. W. Singer, "Income Distribution and Population Growth" (pp. 510-17), there is explicit mention of lower mortality as "a necessary first step towards achieving the more desirable low birth rate/low death rate type of equilibrium" (p. 516). But the author follows this statement by considering effects of a more equal distribution on death rates, with no discussion of the reverse, the possible effects of declines in mortality on the income distribution in the LDCs. Yet, with all the interest in the latter, the possible effects of the trends in mortality rather than in fertility that dominated the demographic changes in the LDCs in the last few decades seem to be neglected.

13. Much of the literature on the response of fertility to mortality declines concentrates on the response of families to the actually incurred death of a child (or children) and the observed reaction. See in this connection Preston's chapter in this volume and the paper for this conference by Yoram Ben-Porath on "Fertility and Child Mortality-Issues in the Demographic Transition of a Migrant Population." Of particular interest also are Preston (1975, pp. 189-200); and his summary introduction to the volume of proceedings of the CICRED seminar on Infant Mortality in Relation to the Level of Fertility (the proceedings were not available to me at the time of writing). For lack of familiarity with the details of most of the sample studies involved, one cannot judge whether the failure to completely "replace" children who die can be translated into an effective absence of a desired number of children as a target firm enough to explain the failure to reduce the birthrate in response to a perceived decline in mortality. There is an apparent lack of symmetry between a situation in which birth frequency has to be raised in an active response to the loss of a child and a situation in which births have to be reduced in response to an increased number of surviving children.

At any rate, it seemed of interest to stress in the brief discussion herc aspects of lag, of perception of mortality declines, and of persistence of an cxcess in the possible number of desired surviving children over that actually resulting through much of the early phase of the downtrend in mortality in the LDCs.

14. The death rates derived for 0-4 population in lines 8 and 17 exceed the crude death rates for total population by factors of 2.4 to 3.2 in $1950-55$ and 2.7 to 3.6 in 1970-75. Multiplying these ratios by the proportion of $0-4$ to total population, averaged over cach of the two quinquennia, we can derive the proportions of deaths of children $0-4$ to all deaths, which would range from well over $40 \%$ to $50 \%$ or morc. The direct data on distribution of deaths by age for various countries in the United Nations Demographic Yearbook (various years) suggest proportions for recent years, back to the $1950 \mathrm{~s}$, of between $40 \%$ and somewhat over $50 \%$. The agreement cannot be checked fully because of scarcity of data on distribution of deaths by age and the indication that in many countries the deaths of infants are particularly underreported (a bias that would affect death rates for 0-4 population much more than total crude death rates). For the present illustrative purposes, further effort at assembling data on deaths by age, or at using direct information on age-specific death rates for LDCs, did not seem worthwhile. A more intensive study of the effects of declines in death rates would warrant such further effort.

15. See a recent paper by Caldwell (1976), which stresses the "flow from the younger generation to the older" in pretransition society and the reverse flow in the posttransition, nucleated families.

16. This choice follows the approach in an earlier brief paper by W. Lee Hansen (1957). This paper was stimulated by a desire to correct an exaggerated and erroneous estimate of the proportional cost of child mortality made rather casually for India by D. Ghosh, who set this cost as high as $22.5 \%$ of national income 
(compared with Hansen's mctium estimate of less than 3\%). Hansen's note employed somewhat more claborate assumptions than are followed here and used data for other countries and dates. But, as will be seen below, the general order of conclusions, when limited to child mortality, is about the same.

The topic here is clearly a part of the wider theme of the economics of family formation in the demographic transition, subject of a brief and illuminating paper by Frank Lorimer (1967).

\section{Comment Albert Fishlow}

Simon Kuznets has made a significant contribution in this essay to the discussion of the economic consequences of recent demographic trends in developing countries. He starts from the dominant role played by mortality decline in bringing about the rapid increase in population in the postwar decades. That enables him to advance three novel propositions relating population growth to the level and internal distribution of income of LDCs.

First, he shows that even instantaneous fertility adjustment to declines in early childhood mortality would not have prevented much of the population expansion actually experienced. Second, he calculates a large economic loss caused by high rates of child and young adult mortality. Third, he conjectures that the reduction in such losses may have accrued disproportionately to poorer families, thereby potentially reducing the inequality of income, especially if measured over the life cycle.

Taken together, these conclusions add up to a rather less negative view of the acceleration of rates of natural increase experienced by developing countries. "One should emphasize to the end the indispensable - and in the longer run beneficial-effects of the declines in the death rates." That perspective, at a time when there is much hand-wringing concerning the population problem, alone is sufficient to make the paper important.

Without denying the positive aspects of mortality decline, I believe casual readers may come away perhaps too persuaded by Kuznets's subtle revisionism. Careful examination of each of the three central propositions is therefore indicated.

The limited potential offset to natural increase afforded by fertility adjustment to declining mortality in the age group 0-4 is the least controversial conclusion. It follows directly from the historical shift downward of the mortality schedule as a whole, not merely at the youngest ages. What Kuznets perhaps does not emphasize enough is that his

Albert Fishlow is professor of economics and director of the Concilium on International and Area Studies at Yale University. 
calculations in table 8.5 imply that the age-specific death rates in the group age $0-4$ declined even proportionally less than for older ages: $26 \%$ (for all regions together) compared with $40 \%$. For Latin America alone, starting from a more favorable initial level, the disparity is much greater: $22 \%$ versus $55 \%$. The recent mortality experience in developing countries has therefore not been dominated by declines in infant and early childhood mortality. That, of course, is why the calculated fertility offset, defined as a response to fewer deaths only in those years, is so limited.

This pattern of mortality decline has not been sufficiently commented upon. One reason is limited information. The Kuznets technique itself is based on age distribution and fertility estimates, not mortality data. Yet the direct calculations reported by the United Nations for those few countries with the requisite information seem to support the Kuznets results. Mortality decline does seem to have been more rapid between ages 15 and 34 than for younger groups.

The disparity with the historical experience of the developed countries is noteworthy. Its implication in this context is that the lag in fertility adjustment to mortality decline will be greater than if improvement had been more concentrated at the youngest ages. It is reasonable to suppose that private calculations aimed at achieving a desired family size will not take into account the improved survival rates of young adults. Completed families may thus come to be larger than anticipated. But since the young adults can go off and be productive, there may well be benefits rather than costs associated with the excess. The survival of these young adults means that a larger number of families, not merely an increase in average size, will characterize the population acceleration. It is only through an indirect route-diffusion of educational and economic opportunities, and increased labor force participation of women, among others-that the countervailing reduction in desired family size can come about.

The characteristics of mortality decline thus influence the extent of resulting population growth. Kuznets contends, however, that reduced mortality produces economic savings. His Appendix details a method for quantifying the reduced wastage. Those calculations seem to me deficient because they do not really measure the economic consequences of mortality decline. The question posed, rather, is What net "consumption inputs might have been avoided if the children and young adults whose deaths we are considering had never been born?" (italics mine). That is, the benefits are contingent upon a simultaneous decline in mortality and fertility, leaving natural increase unchanged. A reduction in mortality alone does not free up resources; the investment in consumption inputs has already been made. Rather, lower death rates influence the potential future return on such streams of inputs. Instead of a zero or 
small return for those dying in childhood or young adulthood, survival extends the period over which surplus may be produced.

There are not two alternative approaches to the measure of the benefits of mortality decline as Kuznets suggests. One cannot use the averted losses, because there is no reason to presume that the realized returns on the surviving investment exactly equal their original cost. The difficult task of identifying the consequences of a higher rate of natural increase emanating from mortality decline is precisely the one of "historical facts and incurred burdens." Kuznets's procedure of fewer births is the one not experienced. Because population increased, supplementary resources had to be found to complement the investments already made. When that occurred, the returns may well have increased; if they did not, then the effects could well have been adverse.

The concentration of mortality decline in the young adult ages is clearly a most favorable one for reaping positive benefits. Much of the investment has already been made, and a productive return upon it has been made possible. The aggregate counterpart is an initial increase in the relative size of the potentially productive population. Even if diminishing returns were encountered, there would bc a net gain so long as the survivors produced more than their own consumption requirements. But if they could not, then the decline in mortality will have worsened the situation by reducing the surplus produced.

The issue cannot be settled without resort to the facts. The variety of theoretical arguments about savings, investment, and production relationships are not in themselves decisive. Assuming a life-cycle pattern of returns determines the outcome. The relevant question is what form it historically took as population increased. While there is no question that an identical rate of population growth generated by mortality decline rather than fertility increase is economically more favorable, there can still be legitimate doubt about the direction of influence of the greater population size.

One is therefore back to the familiar and fundamental problem. We can approach it more intelligently by appreciating that the pattern of mortality decline actually experienced by developing countries may have permitted them to cope with the population explosion more effectively. What is called for is systematic analysis of the economic circumstances of countries whose patterns of mortality decline differed.

Kuznets's final conjecture about possible improvement in the internal income distribution follows from his emphasis upon the economic wastage inherent in high levels of mortality: "The benefit to those who have sustained the losses in the past caused by higher death rates among various economic and social groups meant the reduction of an important aspect of persisting inequality that loomed large in the premodern LDC societies." Our stress upon the resource using character of mortality 
decline makes such a logical sequence, more dubious. This is quite apart from the Kuznets qualification of changing factor prices deriving from the relative scarcity of other factors as labor supply increased.

Three points may be noted. First, it is the richer families that can more easily cope with the greater strains imposed by larger family size resulting from lower death rates. Additional mouths must be fed from the same family output if the potential returns are to be realized. This puts a premium upon access to finance for marginal investment in consumption. Poor families may simply not be able to afford it. Lower levels of average consumption for all survivors likely means inability to take advantage of what opportunities there are. Education will be sacrificed, health will remain poor, skills will continue undeveloped relative to those surviving in families initially better able to respond. Then inequality among incomes over the life cycle will increase. Second, the assumption of uniformity in the pattern of mortality decline is not necessarily correct. Richer families probably already start with much lower infant mortality because of better nutrition; the improvement they experience from improved public health measures may be relatively concentrated in the most productive ages. This could lead to higher returns to them, and again to an increase in inequality. Finally, it may well be that higher-income (and better educated) families are first to adjust their fertility to mortality decline. Then there are tangible savings to be achieved that would accrue to those with higher initial incomes.

This analysis, like that of Kuznets, is couched in terms of income per family member over the life cycle. It therefore abstracts from any instantaneous deterioration in the income distribution of those gainfully employed. The trends here are real in welfare terms and are further aggravated by the increase in land rentals and returns to capital that greater population may be expected to induce, especially where traditional social and economic structures remain intact.

I therefore conclude more pessimistically than he. The inevitable decline in mortality and increase in population, however necessary to modern economic growth, need not have had beneficial consequences for the distribution and level of per capita incomes. But my counterarguments, like his, are very much conjectural. His paper opens up fresh and promising areas for further research. More careful specification of the underlying life-cycle economic-demographic models and their empirical test both rank high on the agenda. It is not the first time, or surely the last, that he has reframed the questions those interested in the process of economic development might fruitfully explore. 


\section{References}

Ajami, I. 1976. Differential fertility in peasant communities: A study of six Iranian villages. Population Studies 30, no. 3 (November): 45363.

Arriaga, Eduardo E., and Davis, Kingsley. 1969. The pattern of mortality change in Latin America. Demography 6, no. 3 (August): 223-42.

Caldwell, John C. 1976. Toward a restatement of demographic transition theory. Population and Development Review 2, nos. 3-4 (Septembcr, December) : 321-66.

Clark, Colin. 1957. Conditions of economic progress. 3d ed. London.

Davis, Kingsley. 1951. Population of India and Pakistan. Princeton: Princeton University Press.

Hansen, W. Lee. 1957. A note on the cost of children's mortality. Journal of Political Economy 65, no. 3 (June) : 257-62.

Kuznets, Simon. 1976. Demographic aspects of the size distribution of income. Economic Development and Cultural Change 25, no. 1 (October ) : $1-94$.

Lorimer, Frank. 1967. The economics of family formation under different conditions. In World population conference, 1965, 2:92-95. New York: United Nations.

Preston, Samuel H. 1975. Health programs and population growth. Population and Development Review 1, no. 2 (December): 189-200. Stolnitz, George H. 1955. A century of international mortality trends. Part 1. Population Studies, vol. 9 (July).

-. 1956. A century of international mortality trends. Part 2. Population Studies, vol. 10 (July).

- 1975. International mortality trends: Some main facts and implications. In The population debate, 1:220-36. New York: United Nations.

Stys, W. 1957. The influence of economic conditions on the fertility of peasant women. Population Studies 11, no. 2 (November) : 136-48.

United Nations. 1953. The determinants and consequences of population trends. 1st ed. New York: United Nations.

United Nations. 1966. World population prospects as assessed in 1963. New York: United Nations.

United Nations. 1969. Growth of the world's urban and rural population, 1920-2000. New York: United Nations.

-_. 1973. The determinants and consequences of population trends. New York: United Nations.

U.S. Bureau of the Census. 1975. Historical statistics of the United States, colonial times to 1970, bicentennial edition, part 1. Washington, D.C. 
